\author{
Marquette University \\ e-Publications@Marquette
}

\title{
$5-2018$
}

\section{Marketers' Use Of Alternative Front-Of-Package Nutrition Symbols: An Examination Of Effects On Product Evaluations}

\author{
Christopher L. Newman \\ University of Mississippi \\ Scot Burton \\ University of Arkansas - Fayetteville \\ J. Craig Andrews \\ Marquette University, craig.andrews@marquette.edu \\ Richard G. Netemeyer \\ University of Virginia - Charlottesville \\ Jeremy Kees \\ Villanova University
}

Follow this and additional works at: https://epublications.marquette.edu/market_fac

Part of the Marketing Commons

\section{Recommended Citation}

Newman, Christopher L.; Burton, Scot; Andrews, J. Craig; Netemeyer, Richard G.; and Kees, Jeremy, "Marketers' Use Of Alternative Front-Of-Package Nutrition Symbols: An Examination Of Effects On Product Evaluations" (2018). Marketing Faculty Research and Publications. 255.

https://epublications.marquette.edu/market_fac/255 


\section{e-Publications@Marquette}

\section{Marketing Faculty Research and Publications/College of Business Administration}

This paper is NOT THE PUBLISHED VERSION; but the author's final, peer-reviewed manuscript. The published version may be accessed by following the link in the citation below.

Journal of the Academy of Marketing Science, Vol. 46, No. 3 (2018): 453-476. DOI. This article is (C) Springer US and permission has been granted for this version to appear in e-Publications@Marquette. Springer US does not grant permission for this article to be further copied/distributed or hosted elsewhere without the express permission from Springer US.

\section{Marketers' use of alternative front-of-package nutrition symbols: An examination of effects on product evaluations}

Christopher L. Newman

University of Mississippi University

Scot Burton

University of Arkansas, Fayetteville

J. Craig Andrews

Marquette University, Milwaukee

Richard G. Netemeyer

University of Virginia, Charlottesville

Jeremy Kees

Villanova University, Villanova 


\begin{abstract}
How front-of-package (FOP) nutrition icon systems affect product evaluations for more and less healthful objective nutrition profiles is a critical question facing food marketers, consumers, and the public health community. We propose a conceptually-based hierarchical continuum to guide predictions regarding the effectiveness of several FOP systems currently used in the marketplace. In Studies $1 \mathrm{a}$ and $1 \mathrm{~b}$, we compare the effects of a broad set of FOP icons on nutrition evaluations linked to health, accuracy of evaluations, and purchase intentions for a single product. Based on these findings, Studies 2 and 3 test the effects of two conceptually-different FOP icon systems in a retail laboratory in which consumers make comparative evaluations of multiple products at the retail shelf. While there are favorable effects of each system beyond control conditions with no FOP icons, results show that icons with an evaluative component that aid consumers' interpretations generally provide greater benefits (particularly in product comparison contexts). We offer implications for consumer packaged goods marketers, retailers, and the public policy and consumer health communities.
\end{abstract}

\title{
Keywords
}

Nutrition labelin,g Nutrition consciousness, Front-of-package nutrition icons, Consumer health, Food marketing, Information disclosure

Over the last 30 years, obesity has increased at an alarming rate in the U.S. According to data from the National Health and Nutrition Examination Survey, more than two-thirds of all adult Americans aged 20 or older are either overweight or obese (Ogden et al. 2014). Forecasts further indicate that one-half of U.S. adults will be obese by 2030 (Finkelstein et al. 2012). When adjusted for age and smoking factors, obesity is associated with an estimated 300,000 deaths each year over normal weight categories, and it has been linked to an increased risk of type 2 diabetes, coronary heart disease, high blood pressure, arthritis, and several types of cancer (Center for Disease Control [CDC] 2017). This obesity trend has escalated in spite of the presence of Nutrition Facts panels (NFPs) that convey nutrition information on food packaging since 1993. As such, addressing the obesity issue and educating consumers about nutrition are major concerns for food marketers (e.g., Stanish 2010; Bittman 2014).

Many consumers find themselves pressed for time when food shopping and/or may not have the knowledge, skills, or motivation required to study and understand back-of-package NFPs. Thus, quick access to useful information about calories and nutrient content on food packages remains an important objective for both marketers and federal nutrition policy in the U.S. and abroad (Food and Drug Administration [FDA] 2011; Kees et al. 2015). To help accomplish this, front-of package (FOP) labeling has become more prevalent. FOP labels are defined as labels appearing on the front of food packages used to complement the NFPs found on the back or side of the package (cf. Grocery Manufacturers Association [GMA] 2011; FDA 2011). With no standardized, government-mandated FOP label, many U.S. manufacturers have offered their own versions to increase the ease of use of nutrition information and potentially aid consumers' decisions at the retail point-of-purchase. However, there is a need to expand current FOP research to a wider variety of formats, moderating conditions, nutritional levels, and number of product choice options. This includes FOP labels such as the quantitative Guideline Daily Amounts icon, as well as more evaluative FOP icons such as the Institute of Medicine's Stars (with and without the NFP). Important consumer characteristics, such as nutrition consciousness (i.e., the motivation to process and utilize nutrition information), may also impact the effects of FOP labeling systems across products of varying objective nutrition levels. Although certain formats have been shown to be useful (cf. Andrews, Burton, and Kees 2011), how a broader variety of 
FOP icon systems affect evaluations of both more and less healthful products in the presence of multiple product alternatives is a critical issue examined in the current research.

Our research extends prior findings in several ways. First, we examine a broader set of FOP-based icons and outcomes of substantial interest to consumer packaged goods (CPG) marketers and the public health communities. Given differences in icon format attributes, in Studies $1 \mathrm{a}$ and $1 \mathrm{~b}$ we predict and test effects of different FOP icons across a range of nutrition profiles on the accuracy of health evaluations and purchase intentions. Second, we consider nutrition consciousness as a potential moderator in assessing how FOP cues may differentially aid certain segments of consumers. Consistent with most prior labeling studies (e.g., Andrews et al. 2011; Kozup et al. 2003; Viswanathan et al. 2009), we examine evaluations of a single product in both of these initial online studies. Third, given that many consumers use nutrition information to compare the healthfulness of multiple product alternatives at the retail point-of-purchase, Studies 2 and 3 extend our findings to a realistic retail laboratory context where consumers use different FOP icons to evaluate multiple products simultaneously. Comparing nutrition information for numerous items in a choice set can be considerably more complex and effortful than evaluating a single product in isolation. Based on our findings, we offer implications for CPG marketers and retailers using voluntary FOP systems, as well as for the public policy and consumer health communities.

\section{Conceptual framework: front-of-package nutrition symbols and icons}

Consumers of packaged food goods in the U.S. have recently faced a barrage of FOP nutrition symbols and icons, including use of the Guideline Daily Amounts (GDA), Hannaford's Guiding Stars, Wal-Mart's "Great for You" Program, the GMA's Facts-Up-Front System, the NuVal Scoring System, and the Institute of Medicine's (IOM) Healthy Stars program (GMA 2011; Facts-Up-Front 2014; IOM 2011; NuVal 2014; Sebolt 2008). ${ }^{1}$ Given the prevalence of FOP icons, there have been some useful experimental studies conducted recently. An overview of key studies is offered in Table 1. For example, previous FOP research has examined the effects of different icon formats and intervening variables (e.g., attention) across a number of outcome variables (e.g., consumer perceptions, product choice, retailer attributes). We extend prior findings by offering a series of complementary studies that examine (1) a wide variety of FOP disclosures that vary in their conceptual characteristics, (2) a range of objective nutrition levels, (3) differing food categories, (4) potentially important moderators and mediators, and (5) differing evaluation contexts (i.e., single vs. multiple products).

Table 1 Summary of key front-of-package (FOP) nutrition disclosure experiments

\begin{tabular}{|c|c|c|c|c|c|c|c|}
\hline $\begin{array}{l}\text { Publicatio } \\
\text { n }\end{array}$ & $\begin{array}{l}\text { Research } \\
\text { Objective }\end{array}$ & $\begin{array}{l}\text { Theory } \\
\text { Used }\end{array}$ & $\begin{array}{l}\text { Study } \\
\text { Context and } \\
\text { FOP Icon(s) } \\
\text { Examined }\end{array}$ & $\begin{array}{l}\text { Design and } \\
\text { Manipulation(s } \\
\text { ) }\end{array}$ & $\begin{array}{l}\text { Levels of } \\
\text { nutrition } \\
\text { profiles of } \\
\text { food }\end{array}$ & $\begin{array}{l}\text { Dependent } \\
\text { Measures; } \\
\text { Mediators }\end{array}$ & Key Findings \\
\hline $\begin{array}{l}\text { Andrews } \\
\text { et al. } \\
(2011)\end{array}$ & $\begin{array}{l}\text { Investigate } \\
\text { how } \\
\text { consumers } \\
\text { evaluate } \\
\text { front-of- } \\
\text { package } \\
\text { summary } \\
\text { icons } \\
\text { versus } \\
\text { nutrient- }\end{array}$ & $\begin{array}{l}\text { Heuristic } \\
\text { processing; } \\
\text { halo } \\
\text { effects; } \\
\text { Elaboratio } \\
\text { n } \\
\text { likelihood } \\
\text { model }\end{array}$ & $\begin{array}{l}\text { Online } \\
\text { experiment; } \\
\text { Smart } \\
\text { Choices; } \\
\text { Traffic Light- } \\
\text { Guideline } \\
\text { Daily } \\
\text { Amounts }\end{array}$ & $\begin{array}{l}3 \text { (front-of- } \\
\text { package } \\
\text { icon) } \times 2 \\
\text { (nutrition facts } \\
\text { panel) } \times 2 \\
\text { (nutrition } \\
\text { consciousness); } \\
\text { front-of- } \\
\text { package icon } \\
\text { manipulation } \\
\text { (control vs. }\end{array}$ & $\begin{array}{l}\text { Single } \\
\text { (moderate } \\
\text { nutrition) } \\
\text { objective } \\
\text { nutrition } \\
\text { level }\end{array}$ & $\begin{array}{l}\text { Perceptions } \\
\text { of overall } \\
\text { healthfulness } \\
\text {; perceptions } \\
\text { of specific } \\
\text { nutrition } \\
\text { levels; } \\
\text { product } \\
\text { evaluations; } \\
\text { accuracy of } \\
\text { using }\end{array}$ & $\begin{array}{l}\text { Smart Choices } \\
\text { icon can lead } \\
\text { to potentially } \\
\text { misleading } \\
\text { positive } \\
\text { nutrient } \\
\text { evaluations; } \\
\text { the Traffic } \\
\text { Light-GDA icon } \\
\text { results in more } \\
\text { accurate }\end{array}$ \\
\hline
\end{tabular}




\begin{tabular}{|c|c|c|c|c|c|c|c|}
\hline & $\begin{array}{l}\text { specific } \\
\text { symbols }\end{array}$ & & & $\begin{array}{l}\text { smart choices } \\
\text { icon vs. traffic } \\
\text { light- icon); } \\
\text { nutrition facts } \\
\text { panel } \\
\text { manipulation } \\
\text { (control vs. } \\
\text { NFP) }\end{array}$ & & $\begin{array}{l}\text { nutrition } \\
\text { information; } \\
\text { no mediation }\end{array}$ & $\begin{array}{l}\text { nutrition } \\
\text { accuracy } \\
\text { scores in the } \\
\text { absence of the } \\
\text { nutrition facts } \\
\text { panel; } \\
\text { nutrition } \\
\text { consciousness } \\
\text { moderates } \\
\text { effects related } \\
\text { to the } \\
\text { nutrition facts } \\
\text { panel }\end{array}$ \\
\hline $\begin{array}{l}\text { Bialkova et } \\
\text { al. (2014) }\end{array}$ & $\begin{array}{l}\text { Investigate } \\
\text { whether } \\
\text { and how } \\
\text { attention } \\
\text { to } \\
\text { nutrition } \\
\text { informatio } \\
\text { n mediates } \\
\text { consumers } \\
\text { 'product } \\
\text { choice. }\end{array}$ & $\begin{array}{l}\text { Bottom-up } \\
\text { and top- } \\
\text { down } \\
\text { processing }\end{array}$ & $\begin{array}{l}\text { Behavioral } \\
\text { laboratory; } \\
\text { Choices } \\
\text { logo; Traffic } \\
\text { Light; } \\
\text { Guideline } \\
\text { Daily } \\
\text { Amounts }\end{array}$ & $\begin{array}{l}\text { Experimental } \\
\text { choice } \\
\text { paradigm } \\
\text { combined with } \\
\text { eye-tracking. } 4 \\
\text { (FOP label) } \times 2 \\
\text { (Brand) } \times 2 \text { (Fat } \\
\text { content) } \times 2 \\
\text { (shopping goal) }\end{array}$ & $\begin{array}{l}2 \text { levels of } \\
\text { fat content } \\
\text { (low vs } \\
\text { medium) }\end{array}$ & $\begin{array}{l}\text { Attention } \\
\text { capture; } \\
\text { product } \\
\text { choice; } \\
\text { mediator of } \\
\text { attention }\end{array}$ & $\begin{array}{l}\text { Respondents } \\
\text { fixated longer } \\
\text { and more } \\
\text { often on } \\
\text { products with } \\
\text { color-coded } \\
\text { FOP labels and } \\
\text { these products } \\
\text { had the } \\
\text { highest } \\
\text { likelihood of } \\
\text { being chosen. } \\
\text { Product choice } \\
\text { was attributed } \\
\text { to the } \\
\text { attention- } \\
\text { getting } \\
\text { property of } \\
\text { the labels. }\end{array}$ \\
\hline $\begin{array}{l}\text { Ducrot et } \\
\text { al. (2016) }\end{array}$ & $\begin{array}{l}\text { Compare } \\
\text { the impact } \\
\text { FOP } \\
\text { nutrition } \\
\text { labels on } \\
\text { consumers } \\
\text { purchasing } \\
\text { intentions. }\end{array}$ & $\mathrm{n} / \mathrm{a}$ & $\begin{array}{l}\text { Virtual web- } \\
\text { based } \\
\text { supermarket } \\
\text {; GDA; } \\
\text { Multiple } \\
\text { Traffic } \\
\text { Lights; Five- } \\
\text { Color } \\
\text { Nutrition } \\
\text { Label; Green } \\
\text { Tick }\end{array}$ & $\begin{array}{l}\text { Subjects } \\
\text { randomly } \\
\text { assigned to } \\
\text { one of five FOP } \\
\text { conditions held } \\
\text { constant across } \\
\text { all products } \\
\text { during the } \\
\text { study }\end{array}$ & $\begin{array}{l}\text { Continuous } \\
\text { (variable) }\end{array}$ & $\begin{array}{l}\text { Overall } \\
\text { nutrition } \\
\text { quality of } \\
\text { shopping } \\
\text { cart; nutrient } \\
\text { content of } \\
\text { the shopping } \\
\text { cart; no } \\
\text { mediation }\end{array}$ & $\begin{array}{l}\text { The Five-Color } \\
\text { nutrition label } \\
\text { led to the } \\
\text { highest overall } \\
\text { nutritional } \\
\text { quality of the } \\
\text { items selected. }\end{array}$ \\
\hline $\begin{array}{l}\text { Dzhogleva } \\
\text { et al. } \\
(2015)\end{array}$ & $\begin{array}{l}\text { Investigate } \\
\text { the effect } \\
\text { of a } \\
\text { simplified } \\
\text { nutrition } \\
\text { scoring } \\
\text { system on } \\
\text { shoppers' } \\
\text { food } \\
\text { decisions } \\
\text { and their } \\
\text { sensitivity }\end{array}$ & $\begin{array}{l}\text { Processing } \\
\text { costs; } \\
\text { Perceptual } \\
\text { saliency; } \\
\text { Heuristics }\end{array}$ & $\begin{array}{l}\text { Quasi- } \\
\text { experimenta } \\
\text { I field study; } \\
\text { NuVal } \\
\text { Nutritional } \\
\text { Scoring } \\
\text { System }\end{array}$ & $\begin{array}{l}\text { Eight measured } \\
\text { independent } \\
\text { variables }\end{array}$ & $\begin{array}{l}\text { Continuous } \\
\text { (variable) }\end{array}$ & $\begin{array}{l}\text { Nutrition } \\
\text { content of } \\
\text { shoppers' } \\
\text { purchases; } \\
\text { Equivilized } \\
\text { units } \\
\text { purchased by } \\
\text { each } \\
\text { shopper per } \\
\text { week; no } \\
\text { mediation }\end{array}$ & $\begin{array}{l}\text { A point-of-sale } \\
\text { nutrition } \\
\text { scoring system } \\
\text { helped } \\
\text { consumers } \\
\text { make } \\
\text { somewhat } \\
\text { healthier food } \\
\text { choices. } \\
\text { Shoppers } \\
\text { became less } \\
\text { price sensitive }\end{array}$ \\
\hline
\end{tabular}




\begin{tabular}{|c|c|c|c|c|c|c|c|}
\hline & $\begin{array}{l}\text { to price } \\
\text { and } \\
\text { promotion. }\end{array}$ & & & & & & $\begin{array}{l}\text { and more } \\
\text { promotion } \\
\text { sensitive } \\
\text { following the } \\
\text { introduction of } \\
\text { the food } \\
\text { scoring } \\
\text { system. }\end{array}$ \\
\hline $\begin{array}{l}\text { Graham et } \\
\text { al. (2015) }\end{array}$ & $\begin{array}{l}\text { Investigate } \\
\text { whether } \\
\text { FOP labels } \\
\text { would help } \\
\text { consumers } \\
\text { select } \\
\text { more } \\
\text { healthy } \\
\text { foods and } \\
\text { whether } \\
\text { in-aisle } \\
\text { signage } \\
\text { that } \\
\text { explained } \\
\text { the FOP } \\
\text { labels } \\
\text { would } \\
\text { impact } \\
\text { FOP } \\
\text { effects. }\end{array}$ & $\mathrm{n} / \mathrm{a}$ & $\begin{array}{l}\text { Simulated } \\
\text { shopping } \\
\text { lab; Facts Up } \\
\text { Front; } \\
\text { Multiple } \\
\text { Traffic Lights }\end{array}$ & $\begin{array}{l}2 \text { (FOP } \\
\text { label) } \times 2 \text { (in- } \\
\text { aisle } \\
\text { explanatory } \\
\text { signage) }\end{array}$ & $\begin{array}{l}\text { Single } \\
\text { (moderatel } \\
\text { y } \\
\text { nutritious) } \\
\text { objective } \\
\text { nutrition } \\
\text { level }\end{array}$ & $\begin{array}{l}\text { Food } \\
\text { healthfulness } \\
\text {, product } \\
\text { choice; no } \\
\text { mediation }\end{array}$ & $\begin{array}{l}\text { Neither FOP } \\
\text { label led to } \\
\text { food choices } \\
\text { with lower } \\
\text { saturated fat, } \\
\text { sodium, or } \\
\text { sugar. In-aisle } \\
\text { signs were } \\
\text { somewhat } \\
\text { helpful to } \\
\text { consumers in } \\
\text { making more } \\
\text { healthy dietary } \\
\text { decisions. }\end{array}$ \\
\hline $\begin{array}{l}\text { Kees et al. } \\
(2014)\end{array}$ & $\begin{array}{l}\text { Investigate } \\
\text { moderatin } \\
\mathrm{g} \text { influence } \\
\text { of } \\
\text { objective } \\
\text { nutrition } \\
\text { knowledge } \\
\text { and } \\
\text { consumer } \\
\text { education } \\
\text { on FOP } \\
\text { nutrition } \\
\text { disclosures } \\
\text {. }\end{array}$ & $\begin{array}{l}\text { Informatio } \\
\mathrm{n} \\
\text { truncation }\end{array}$ & $\begin{array}{l}\text { Online } \\
\text { experiments } \\
\text {; Facts Up } \\
\text { Front (long } \\
\text { and short } \\
\text { versions); } \\
\text { Traffic Light } \\
\text { system (long } \\
\text { and short } \\
\text { versions) }\end{array}$ & $\begin{array}{l}\text { Study 1: } 5 \text { (FOP } \\
\text { conditions) } \times 2 \\
\text { (nutrition } \\
\text { knowledge); } \\
\text { Study 2: } 5 \text { (FOP } \\
\text { conditions) } \times 2 \\
\text { (consumer } \\
\text { education } \\
\text { prime) }\end{array}$ & $\begin{array}{l}\text { Single } \\
\text { (moderatel } \\
\text { y } \\
\text { nutritious) } \\
\text { objective } \\
\text { nutrition } \\
\text { level }\end{array}$ & $\begin{array}{l}\text { Attention to } \\
\text { nutrition } \\
\text { information; } \\
\text { ease of } \\
\text { judging } \\
\text { product } \\
\text { healthfulness } \\
\text {; } \\
\text { engagement } \\
\text { with } \\
\text { nutrition } \\
\text { information; } \\
\text { information } \\
\text { usefulness } \\
\text { perceptions; } \\
\text { no mediation }\end{array}$ & $\begin{array}{l}\text { All FOP } \\
\text { disclosures } \\
\text { had positive } \\
\text { effects on } \\
\text { outcome } \\
\text { variables } \\
\text { (relative to a } \\
\text { control } \\
\text { condition). } \\
\text { Objective } \\
\text { nutrition } \\
\text { knowledge } \\
\text { and primed } \\
\text { nutrition } \\
\text { education } \\
\text { moderate FOP } \\
\text { disclosure } \\
\text { effects. }\end{array}$ \\
\hline $\begin{array}{l}\text { Newman } \\
\text { et al. } \\
(2014)\end{array}$ & $\begin{array}{l}\text { Investigate } \\
\text { how } \\
\text { shopper } \\
\text { marketing } \\
\text { efforts } \\
\text { associated } \\
\text { with FOP } \\
\text { labeling } \\
\text { systems }\end{array}$ & $\begin{array}{l}\text { Attribution } \\
\text { theory }\end{array}$ & $\begin{array}{l}\text { Study 1: } \\
\text { Online } \\
\text { experiment; } \\
\text { Study 2: } \\
\text { simulated } \\
\text { retail } \\
\text { shopping } \\
\text { lab; Facts Up }\end{array}$ & $\begin{array}{l}\text { Study 1: } 4 \text { FOP } \\
\text { package } \\
\text { conditions; } \\
\text { Study } 2: 2 \\
\text { (evaluative FOP } \\
\text { icon) } \times 2 \\
\text { (reductive FOP } \\
\text { icon) } \times 2 \\
\text { (objective }\end{array}$ & $\begin{array}{l}2 \text { (more vs } \\
\text { less } \\
\text { healthful) }\end{array}$ & $\begin{array}{l}\text { Retailer } \\
\text { evaluations; } \\
\text { mediators of } \\
\text { attitude } \\
\text { toward } \\
\text { retailer and } \\
\text { perceived } \\
\text { retailer } \\
\text { concern for }\end{array}$ & $\begin{array}{l}\text { FOP systems } \\
\text { have direct } \\
\text { and } \\
\text { moderating } \\
\text { effects on } \\
\text { attitude } \\
\text { toward the } \\
\text { retailer and } \\
\text { perceived }\end{array}$ \\
\hline
\end{tabular}




\begin{tabular}{|c|c|c|c|c|c|c|c|}
\hline & $\begin{array}{l}\text { affect } \\
\text { consumer } \\
\text { perception } \\
\text { s of food } \\
\text { choices } \\
\text { and the } \\
\text { retailer. }\end{array}$ & & $\begin{array}{l}\text { Front; IOM } \\
\text { Stars }\end{array}$ & $\begin{array}{l}\text { product } \\
\text { healthfulness) }\end{array}$ & & $\begin{array}{l}\text { patronage } \\
\text { intent; } \\
\text { Product } \\
\text { evaluations }\end{array}$ & $\begin{array}{l}\text { retailer } \\
\text { concern for } \\
\text { the shoppers. } \\
\text { These retail } \\
\text { variables } \\
\text { mediate the } \\
\text { effects of the } \\
\text { FOP system on } \\
\text { shoppers' } \\
\text { intentions. }\end{array}$ \\
\hline $\begin{array}{l}\text { Newman } \\
\text { et al. } \\
(2016)\end{array}$ & $\begin{array}{l}\text { Investigate } \\
\text { the effects } \\
\text { of } \\
\text { different } \\
\text { types of } \\
\text { FOP } \\
\text { nutrition } \\
\text { cues } \\
\text { across } \\
\text { consumers } \\
\text { processing } \\
\text { contexts }\end{array}$ & $\begin{array}{l}\text { Processing } \\
\text { fluency; } \\
\text { Resource } \\
\text { matching }\end{array}$ & $\begin{array}{l}\text { Studies 1a \& } \\
\text { 1b: Online } \\
\text { experiment; } \\
\text { Study } 2 \\
\text { simulated } \\
\text { retail } \\
\text { shopping lab } \\
\text { environmen } \\
\text { t Objective; } \\
\text { IOM Stars }\end{array}$ & $\begin{array}{l}\text { Studies } 1 \text { a \& } \\
\text { 1b: } 2 \text { (objective } \\
\text { FOP cue) } \times 2 \\
\text { (evaluative FOP } \\
\text { cue); Study } 2: 2 \\
\text { (processing } \\
\text { context) } \times 3 \\
\text { FOP cue) }\end{array}$ & $\begin{array}{l}2 \\
\text { (moderatel } \\
\text { y heathy; } \\
\text { less } \\
\text { healthy) }\end{array}$ & $\begin{array}{l}\text { Product-level } \\
\text { fluency; Set- } \\
\text { level fluency; } \\
\text { healthfulness } \\
\text { evaluations; } \\
\text { purchase } \\
\text { intentions; } \\
\text { no mediation }\end{array}$ & $\begin{array}{l}\text { Cues that offer } \\
\text { quantitative } \\
\text { information } \\
\text { lead to higher } \\
\text { evaluations in } \\
\text { a } \\
\text { noncomparitiv } \\
\text { e contexts. In } \\
\text { contrast, } \\
\text { evaluative } \\
\text { nutrition clues } \\
\text { lead to higher } \\
\text { evaluations in } \\
\text { comparative } \\
\text { contexts. }\end{array}$ \\
\hline $\begin{array}{l}\text { Pettigrew } \\
\text { et al. } \\
(2017)\end{array}$ & $\begin{array}{l}\text { Investigate } \\
\text { which } \\
\text { evaluation } \\
\text { criteria are } \\
\text { considered } \\
\text { most } \\
\text { important } \\
\text { to } \\
\text { consumers } \\
\text { and the } \\
\text { relative } \\
\text { importanc } \\
\text { e placed } \\
\text { on these } \\
\text { criteria. }\end{array}$ & $\mathrm{n} / \mathrm{a}$ & $\begin{array}{l}\text { Online } \\
\text { experiment; } \\
\text { Daily intake; } \\
\text { Traffic light; } \\
\text { Health Star } \\
\text { Rating }\end{array}$ & $\begin{array}{l}\text { Within subjects } \\
\text { evaluation of } \\
\text { eight packages } \\
\text { with FOP labels }\end{array}$ & Variable & $\begin{array}{l}\text { FOP label } \\
\text { preference; } \\
\text { FOP } \\
\text { attribute } \\
\text { importance } \\
\text { ratings; no } \\
\text { mediation }\end{array}$ & $\begin{array}{l}\text { The Health } \\
\text { Star Rating } \\
\text { was the most } \\
\text { preferred FOP } \\
\text { label due to } \\
\text { the ease of } \\
\text { use, } \\
\text { interpretive } \\
\text { content, and } \\
\text { salience. }\end{array}$ \\
\hline
\end{tabular}

The combination of factors listed above helps extend the prior research shown in Table 1. For example, Andrews et al. (2011) used a dual processing framework to test how two FOP icons (a primarily reductive traffic light GDA format and an evaluative Smart Choices dichotomous format) lead to differences in information processing versus a no FOP control. However, given the number of treatment conditions, and a different study focus, Andrews and colleagues evaluated only a single product and held its nutrition level constant across all FOP conditions. In contrast, we extend this research by assessing whether FOPs aid consumers in evaluating and choosing a more healthful product alternative. Specifically, we seek to understand how icons with differing characteristics help different consumer groups (e.g., high vs. low nutrition consciousness) distinguish between products of varying objective healthfulness (NLEA 1990; FDA 2015). This additional insight cannot be directly gained when only a single nutritional profile or a very limited set of FOP icons is used. 


\section{Conceptual characteristics of reductive and evaluative front-of-package icons}

In general, FOP symbols and icons can be classified as either (1) reductive icons (e.g., Facts-Up-Front, Guideline Daily Amounts) that present a reduced amount, or "snapshot," of nutrient-specific information from the NFP or (2) evaluative icons (e.g., Smart Choices, IOM, NuVal) that provide consumers with an overall evaluation of a product's healthfulness (e.g., Andrews et al. 2014; Newman, Howlett, and Burton 2014). Because of its increasing use in the U.S. marketplace, the reductive FactsUp-Front (FUF) system is of particular interest in the current research. Reductive FOP icons, such as the FUF, help consumers by reducing the amount of information to be processed, relative to the NFP on the back of the package, and it has been positioned to help consumers understand nutrient levels and aid in the fight against obesity (GMA 2011). Specifically, the FUF icon places the more critical nutrition information (calories, saturated fat, sodium, sugar) on the FOP where it is more easily accessed than the NFP on the back or side of packages. Consumers should be able to more easily find and process this less complex, condensed information in the FUF icon compared to when the many types of nutrient and vitamin data are only available in the NFP.

Evaluative FOP icons provide a simplified, interpretive compilation of nutrition information, which can more directly aid many consumers in the assessment of products. For example, the IOM's Healthy Stars system provides calorie information and assigns 0 stars (least healthy) to 3 stars (most healthy) to a given product based on its levels of certain key nutrients. This evaluative information offers consumers a distinct benefit when they are faced with the task of differentiating between multiple brands in a choice set at the retail shelf. Overall, the reductive system, and the even less complex evaluative system, would both seem to make consumers' processing tasks easier and aid in discrimination between the healthfulness of different product alternatives (compared to only examining the NFP on the back of packages).

Based on these differences, we draw from an accessibility/diagnosticity theoretical framework (Alba, Hutchinson, and Lynch 1991; Keller et al. 1997) to propose a hierarchy of effectiveness for nutrition information communicated to consumers on food product packaging. As shown in Fig. 1, the hierarchical continuum ranges from no NFP/FOP information at all (control conditions), to FOP icons that are primarily reductive in nature (e.g., FUF), to those that are reductive combined with evaluative components (e.g., Traffic Lights with GDAs), to those that are primarily evaluative in nature (e.g., IOM Stars). Regardless of format, any FOP icon should enhance accessibility (relative to the NFP alone) by offering nutrition information on the front, rather than the back or side, of food packages. FOP icons should also enhance diagnosticity compared to the NFP-though to a different extent-by reducing the amount and complexity of nutrition information. Specifically, we propose that the inherent structural attributes of the NFP and different types of FOP formats lead to differences in how specific, quantitative, evaluative, and abstract the conveyed nutrition information is perceived to be by consumers. Consequently, as discussed below, there should be differences in the extent to which the FOPs aid consumers in determining product healthfulness when objective nutrition values vary across products. A conceptual overview of how the accessibility and diagnosticity of available nutrition information may affect consumers' healthfulness evaluations of products with varying nutrition profiles is presented in Fig. 1. 


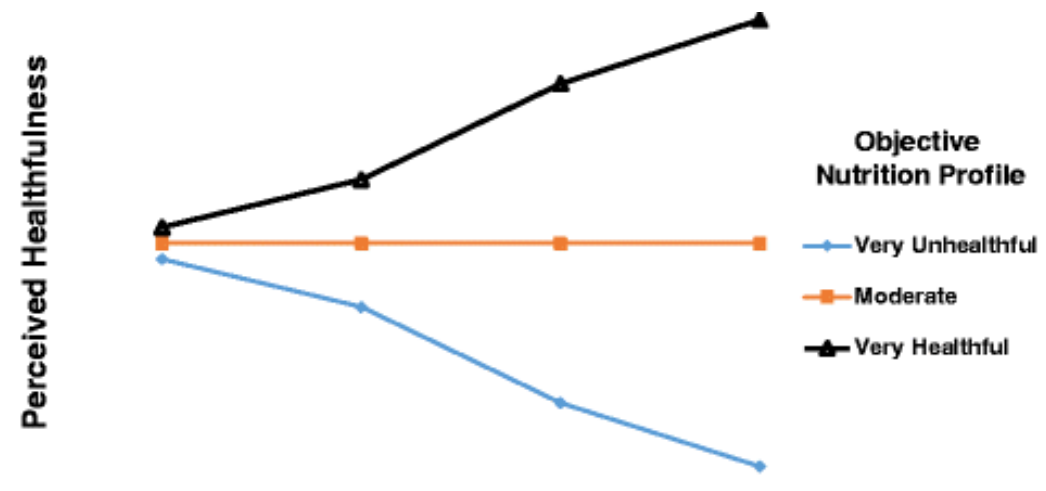

\begin{tabular}{|c|c|c|c|}
\hline No NFP/FOP & NFP Only & Reductive FOP & Evaluative FOP \\
\hline & $\begin{array}{l}\text { More specific, } \\
\text { quantitative } \\
\text { information }\end{array}$ & $<-------->$ & $\begin{array}{c}\text { More abstract, } \\
\text { evaluative } \\
\text { information }\end{array}$ \\
\hline
\end{tabular}

Nutrition Information Disclosures

\begin{abstract}
Note: The No NFP/FOP control condition offers no FOP information and assumes that consumers choose not to examine the NFP on the back of the package; the NFP Only condition has NFP information available and consumers may choose to examine it, but there is no FOP information available; the reductive FOP reduces critical quantitative nutrition information (e.g., calories, saturated fat, sodium, sugar) from the NFP and places it on the front of the package (e.g., the Facts-up-Front icon); and the evaluative FOP provides information that helps consumers evaluate the meaning of the nutrient levels (e.g. the 0 to 3 stars format recommended by the Institute of Medicine), but offers no quantitative values for the nutrients. In terms of the accessibility/diagnosticity conceptual framework, all FOP conditions, relative to the NFP and FOP controls, make the nutrition information more accessible, and the evaluative FOPs are more diagnostic that the reductive FOPs, which in urn, are more diagnostic than the NFP alone.
\end{abstract}

Fig. $1 \mathrm{~A}$ hierarchical continuum of predicted effects of front of package nutrition information

At the beginning of the continuum in the "No NFP/FOP" condition, consumers should be unable to determine the relative healthfulness of products within a category when there is no nutrition information available on the FOP or in the NFP on the back of the package. This is consistent with situations in which the many shoppers at retail stores choose not to examine the NFP on the back of packages (and no FOP icon is offered). Here, the accessibility and diagnosticity of nutrition information is at its lowest. Some researchers have pointed out weaknesses of the NFP, arguing that it has not been fully successful in accomplishing NLEA objectives for more vulnerable consumers who may find it difficult to use the large amount of specific, quantitative NFP information to determine the relative healthfulness of products (e.g., Viswanathan, Hastak, and Gau 2009). However, prior research indicates that accessing the NFP (versus control conditions in which the NFP is not accessed) can help consumers determine the healthfulness of product alternatives (Mitra et al. 1999; Burton, Garretson, and Velliquette 1999). As suggested in Fig. 1 in the "NFP Only" condition, we anticipate that examining the NFP on the back of the package in the absence of FOP information should help in determining the relative healthfulness of a given product.

Time constraints and limited nutrition knowledge, however, may make it difficult for consumers to quickly access and interpret the more specific, quantitative NFP information. Thus, offering FOP nutrition information that is more accessible and diagnostic should help consumers' evaluations (Andrews et al. 2014). As noted earlier, reductive icons considerably decrease the amount and complexity of the detailed nutrient and vitamin information offered in the NFP, and make it more accessible on the FOP. Reductive FOP icons, such as the FUF, should therefore be more diagnostic and useful for consumer healthfulness evaluations relative to the NFP-especially for simpler tasks like evaluating a single product in isolation. However, the diagnosticity of reductive icons should decrease somewhat as the amount of information (Scammon 1977) and complexity of the task increases 
(particularly relative to simpler evaluative icons). That is, consumers should find the quantitative information in reductive icons less useful when comparing many different products in a category.

The next level in the hierarchical continuum includes FOP icons that add an evaluative component to the information presented by reductive icons (e.g., Traffic Lights, IOM stars). For example, the Traffic Light FOP icon is a government-endorsed, voluntary system currently used in the United Kingdom that presents absolute nutrient levels and \% Daily Value information, while simultaneously offering a color scheme to indicate nutrient healthfulness (EUFIC 2015). More specifically, the Traffic Light format uses color-coding to indicate whether a given nutrient (e.g., sodium, sugar) is "low" (green), "moderate" (amber), or "high" (red) in its level based upon an objective standard. Thus, it further clarifies the quantitative nutrient information from the NFP by condensing it and adding an evaluative component to it. Conceptually, this evaluative attribute should increase information diagnosticity and aid in the processing and interpretation of individual nutrient levels (e.g., for consumers with low awareness of desirable levels for specific nutrients linked to long-term health such as sodium or sugar). This helps address the original objectives of the NLEA (1990) to reduce consumer confusion and aid in interpretation of nutrition information.

Lastly, some evaluative FOP disclosures (see the end of the Fig. 1 continuum) offer even greater simplicity and potential diagnostic benefits to the consumer by providing an overall assessment of the healthfulness of a product. As mentioned, the IOM system assigns 0 to 3 stars to a product to indicate a product's overall objective healthfulness based on key nutrient levels. Australia and New Zealand have similarly opted for a voluntary star-based system that will become mandatory after a five-year introductory period (EUFIC 2015). These evaluative disclosures reduce the amount and complexity of information by summarizing and interpreting the overall healthfulness of a product. Thus, as processing tasks become more complex, the relative diagnostic benefits of such evaluative icons should increase. This enhanced diagnosticity is particularly important for consumers who want to compare several alternatives in a choice set at the retail shelf in an effort to choose the most healthful product. However, note that while evaluative FOP icons are more interpretive than reductive icons, hybrid icons, and the NFP, they are also more abstract (i.e., they do not provide detailed, specific quantitative nutrient information). This makes evaluative icons potentially less diagnostic in situations where consumers have more cognitive resources to commit to processing more detailed nutrition information (e.g., when engaging in the simpler task of evaluating a single product). Evaluative icons are also less diagnostic for at-risk consumers (e.g., diabetics, hypertensive consumers) who need to evaluate the level of a specific nutrient (e.g., sugar, sodium). ${ }^{2}$

In sum, the nature of the nutrition information shown in Fig. 1 transitions from being more specific and quantitative in the "NFP Only" condition to more abstract and evaluative in the "Evaluative FOP" condition. We propose these differences in formats lead to differences in the likelihood that consumers can effectively distinguish between products of varying objective healthfulness, such that the benefit of more abstract evaluative information is enhanced as the evaluation task becomes more challenging.

\section{Overarching proposition and hypotheses}

Drawing from the conceptualization above, we offer the following predictions regarding the moderating effect of different information disclosures for products of varying objective nutrition profiles. In general, the relative accuracy of consumers' healthfulness evaluations should be enhanced by the provision of nutrition information, but the strength of these effects should differ based on the 
specific attributes of the icon systems. The discrimination between a product with a very unfavorable (i.e., unhealthy) objective nutrition profile and a very favorable (i.e., healthy) objective nutrition profile should increase monotonically from a no disclosure condition (e.g., no NFP/FOP; NFP only) to inclusion of FOP information. Due to the differences in attribute characteristics discussed above, the greatest level of discrimination is anticipated for an evaluative FOP disclosure that offers an overall summary evaluation of the product. Consistent with Fig. 1, we propose:

H1a: Compared to a control group with no nutrition information, the inclusion of reductive or evaluative FOP icons for a product with an unfavorable (favorable) objective nutrition profile will decrease (increase) perceived healthfulness and nutrient evaluations (i.e., calories, saturated fat).

H1b: Compared to a control group with no nutrition information, having only the NFP available for a product with an unfavorable (favorable) objective nutrition profile will decrease (increase) perceived healthfulness and nutrient evaluations.

$\mathrm{H} 2$ : Compared to when only the NFP is available, the inclusion of either a reductive or evaluative FOP icon for a product with an unfavorable (favorable) objective nutrition profile will decrease (increase) perceived healthfulness.

H3: Compared to when a reductive FOP icon is available, the inclusion of an evaluative FOP icon for a product with an unfavorable (favorable) objective nutrition profile will decrease (increase) perceived healthfulness.

The above predictions increase our understanding of how the provision of alternative information communication formats affect consumers' evaluations. They also address a primary NLEA objective to enhance consumers' comprehension of product nutrition information (Burton et al. 2015). However, the NLEA also was designed to have some impact beyond comprehension (i.e., "assist consumers in maintaining healthy dietary practices") (NLEA 1990; Federal Register 2010). Therefore, we expect the most effective FOP systems to extend to other important outcomes crucial to health and consumer well-being (Burton et al. 2006; Mitra et al. 1999). In particular, we anticipate that while there will be some attenuation of the predicted moderation, the interaction effects addressed in the predictions above should also extend to other outcomes linked to health (e.g., accuracy of calorie and saturated fat evaluations; disease risk perceptions; purchase intentions).

\section{Moderating role of consumers' nutrition consciousness}

We define nutrition consciousness as the general disposition to attend to nutrition information that reflects goal-directed interests (cf. Andrews, Burton, and Kees 2011). Nutrition conscious consumers will exhibit substantial concern and interest in available nutrition information, and are more likely to be motivated to use it in product evaluations (Newman 2000). Given this interest and motivation, nutrition conscious consumers should be better able to recognize differences between more and less objectively healthful products. Such predictions are supported by the Elaboration Likelihood and Heuristic-Systematic Models, which suggest that consumers' motivational intensity leads to more elaboration and effortful processing of information to form judgments (Eagly and Chaiken 1993; Petty and Cacioppo 1986). Without sufficient interest and concern about nutrition, the type of disclosure (i.e., evaluative vs. reductive) should have less effect on healthfulness perceptions and purchase intentions. As applied to NFP and other nutrition disclosures, favorable nutrient levels can have a positive impact on product attitudes and purchase intentions for motivated consumers, yet have little 
effect for those lower in motivation (Keller et al. 1997). As a result, $\mathrm{H} 4$ predicts that nutrition consciousness moderates effects of a product's objective nutrition profile.

$\mathrm{H} 4$ : Nutrition consciousness moderates the effect of the objective nutrition profile on perceived healthfulness, nutrient evaluations, and purchase intentions. For consumers higher in nutrition consciousness, evaluations are more (less) positive for a product that is more (less) favorable in its objective nutrition profile.

\section{Study $1 a$}

\section{Method}

Pilot study

We conducted an initial online pilot study (Amazon Turk; 84 participants) to support the proposed differences in perceived accessibility and diagnosticity related to nutrition format attributes suggested in Fig. 1. As expected, repeated measure analyses revealed that the NFP was viewed as more specific (all $p$-values $<.01$ ) and quantitative (all $p$-values < .05) than each of the tested FOP formats (i.e., the FUF, Traffic Light, and IOM Stars). Also as expected, the IOM stars format was perceived as more evaluative (all $p<.05$ ) and abstract (all $p<.001$ ) than all other formats. These findings provide general support for our conceptual framework regarding differences in label formats.

\section{Design}

Study 1a assessed a comprehensive array of FOP disclosures offered in the current marketplace and our proposed hierarchy for FOP information. Thus, we conducted a 6 (Front of Package nutrition format) $\times 3$ (objective nutrition profile) $\times 2$ (consumer nutrition consciousness) between-subjects experiment. The six FOP conditions include formats that are being used and/or are of current interest to marketers, public health community, and academic researchers (IOM 2011; Kees et al. 2014). These include the current FUF reductive format (using all white labeling); an identical FUF format with an all green label; the Traffic Light that includes an evaluative component indicating the favorability of the nutrients (red, yellow, green shading); and the IOM's evaluative icon that displays between 0 and 3 stars to signify the overall healthfulness of a product. When nutrition values were displayed for calories, saturated fat, sodium, and sugar on the FOP, they were identical to the levels found in the NFP on the back of the package. The Traffic Light and Stars FOP condition were each based around the favorability of the nutrient levels shown in the NFP.

In addition to these four FOP icon conditions, we included two control conditions. In the "NFP Only" condition shown in Fig. 1, this first control condition did not offer any FOP nutrition information, but the standard NFP was available on the back of the package (participants were asked if they wanted to examine the back of the package; if they responded "Yes," the back of the package with the NFP was shown on their screen). For the "No NFP/FOP" condition in Fig. 1, the second control condition included no information on the FOP and no nutrition information on the back of the package (if participants indicated they wanted to see the back of the package, they were shown an identical version of the back of the package with the NFP removed). This latter control group allows us to compare consumers who do not access any nutrition information for products when shopping (and thus have little objective basis for their evaluations) to other consumers that have received various forms of nutrition information disclosures in other conditions. Other than the FOP nutrition format, all other package information (product shot, description, product weight, fictitious brand name, etc.) was invariant. Examples of the FOP conditions are shown in Web Appendix A2. 
The product nutrition profile conditions were manipulated by altering the nutrient levels for calories, fat, saturated fat, sodium, and sugar found in the NFP (see Web Appendix B). The objective values of these nutrients were similar to levels found in the marketplace for different brands of the product (a Salisbury steak frozen meal product). The fat, saturated fat, and sodium levels ranged up to $50 \%$ of the daily value in the "Very Poor" condition and all were $10 \%$ or below in the "Very Good" condition. Other nutrients shown in the NFP (e.g., cholesterol, fiber, protein) were invariant. A single serving item was used to heighten comparability with previous nutrition research and to minimize serving size issues (a frozen dinner meal product) (Andrews et al. 2011; Mitra et al. 1999).

Also, consistent with prior labeling research, nutrition consciousness was measured rather than manipulated (Andrews et al. 2011). Drawing from research examining possible moderating influences of nutrition interest (Keller et al. 1997), three seven-point scale items were used to assess motivation and interest in processing the nutrition information (e.g., "In general, how interested are you in reading nutrition and health-related information at the grocery store?" anchored by "not interested" and "very interested"). Coefficient alpha for the three item measure was .91. A median split of the sum of the three items was performed and the measure was recoded to reflect a low or high level of enduring motivation (lacobucci et al. 2015). ${ }^{3}$

\section{Sample, procedure, and dependent measures}

The instructions informed the respondents that they would be shown a food package and then asked some questions regarding their opinions and beliefs about the package with no mention of nutrition or labeling. Participants were recruited from Amazon Turk (MTurk) and compensated for their participation. While there has been some debate about the use of MTurk for academic studies, several recent studies support the relative quality of responses (e.g., Goodman and Paolacci 2017; Kees et al. $2017 a, b)$. The sample consisted of 469 consumers who responded to the internet survey ranging in age from 19 to 73 (mean = 36 years). Slightly more than half were female ( $52 \%$ female; $48 \%$ male) with a median income of $\$ 35,001-\$ 50,000$. The vast majority reported having at least some college-level education (86\%).

We employed a mix of single item measures (e.g., evaluations of calories and nutrients) and multi-item scales (e.g., perceived nutrition level; purchase intentions) drawn from prior nutrition disclosure studies (e.g., Kozup et al. 2003). All reliabilities of multi-item measures were acceptable, exceeding .90. Specific measures are shown in Web Appendix C.

\section{Results}

\section{Data checks and initial analyses}

We first examined the effect of the FOP format on participants' request to examine the back of the package (Roe, Levy and Derby 1999; Federal Register 2010). The interest in examining the back of the package was very high across the FOP conditions, ranging from $86 \%$ to $94 \%$, and differences were nonsignificant $\left(\chi^{2}(5)=4.45, p>.20\right)$. This indicates that the presence of the FOP information did not affect interest in the more detailed NFP information, at least in this specific experimental context (Kees et al. 2014). We also performed an initial preliminary test of the nutrition profiles to insure that the manipulation of the levels was noticed by the participants. There was a significant difference $(F(2466)=40.12 ; p<.001$ ) between the three profiles on a measure of general healthiness ("Overall, this product is:" with endpoints of "very unhealthy for me" and "very healthy for me.") All contrasts between means were significant (all $p$-values <.001). The mean for the more favorable objective 
nutrition profile $(M=4.30)$ was greater than the moderate profile $(M=3.46)$, and the less favorable nutrition profile $(M=2.84)$ was viewed as less healthy than the moderate profile. These results provided initial indication that participants generally perceived differences in the three objective profiles as desired.

The initial overarching proposition and Fig. 1 indicate that the inclusion of any of the viable FOP disclosures now in use by food marketers potentially aid consumers because they make more compressed information easier to obtain and process. Time constraints, limited effort, and level of nutrition consciousness may make it difficult for consumers to quickly access and interpret NFP information. Thus, increasing the accessibility of nutrition information on the FOP should help consumers in their evaluations. As suggested in our general proposition, initial analyses tested the effect of the FOP conditions in aggregate compared against both (1) the no FOP control condition (NFP Only) and (2) the full control where there is no nutrition information available at all (No NFP/FOP).

The multivariate interaction between the combined FOP conditions, the NFP Only (with no FOP) condition, and the No NFP/FOP condition across the three objective profile conditions was significant (Wilks $\lambda=.87 ; \mathrm{F}=3.23 ; p<.001$ ). In follow-up contrasts, when FOP information was available, the differences across the three objective nutrition profiles reached significance for all healthfulness and nutrient content measures, as well as the more general evaluation measure (e.g., purchase intent) (Fs range from 10.3 to 89.3; all $p<.001$ ). In the NFP Only condition, differences across the objective nutrition profiles reached significance, though weaker, for all the three nutrition measures [overall healthfulness $(F=3.62, p<.05)$; saturated fat evaluation $(F=5.4, p<.01)$, calorie evaluation $(F=8.75$, $p<.01)$ ]. As would be expected, no significant differences emerged across the objective profiles in the No NFP/FOP control condition (all $p>.20$ for all outcomes), suggesting that the information presented in the NFP is somewhat helpful to evaluations, particularly for specific nutrient evaluations. However, note that for purchase intent, only the FOP present conditions resulted in significant differences across the objective profiles. These initial findings support the proposition that FOP disclosures, in general, provide important supplemental information that can benefit consumers beyond the NFP alone.

\section{Effects on nutrition evaluations and perceived healthfulness of the product} Beyond these overall aggregated FOP effects, the conceptualization in Fig. 1 and Hypotheses 1-3 concern effects of the specific types of FOP labeling systems on the overall healthfulness, calorie, and nutrient evaluations (e.g., saturated fat) across the different objective nutrition profiles (see Web Appendices A2 and B). Results are shown in Table 2. Providing initial support for a moderating role of the specific FOP systems, Table 2 shows significant interactions for all healthfulness and nutrientrelated evaluations. Plots for overall healthfulness and calories are shown in Fig. 2. (The plot for saturated fat is offered in Web Appendix Fig. 1.)

Table 2

Study 1a: Effects of front-of-package nutrition information, objective nutrition profile, and nutrition consciousness on healthfulness and purchase intentions

\begin{tabular}{|l|l|l|l|l|}
\hline ANOVA Results & Oalorie & $\begin{array}{l}\text { Saturated Fat } \\
\text { Evaluations }\end{array}$ & $\begin{array}{l}\text { Purchase } \\
\text { Intentions }\end{array}$ \\
\hline $\begin{array}{l}\text { Independent } \\
\text { Variables }\end{array}$ & $\begin{array}{l}\text { Overall Perceived } \\
\text { Healthfulness }\end{array}$ & $\begin{array}{l}\text { Calorionations } \\
\text { Evaluations }\end{array}$ & & \\
\hline Main Effects & & & \\
\hline
\end{tabular}




\begin{tabular}{|l|l|l|l|l|}
\hline $\begin{array}{c}\text { Front of Package } \\
\text { Icon (FOP) }\end{array}$ & 0.40 & $2.50^{\mathrm{b}}$ & 1.66 & $4.03^{\mathrm{a}}$ \\
\hline $\begin{array}{c}\text { Objective Nutrition } \\
\text { Profile (ONP) } \\
\begin{array}{c}\text { Nutrition } \\
\text { Consciousness (NC) }\end{array}\end{array}$ & $27.14^{\mathrm{a}}$ & $40.7^{\mathrm{a}}$ & $77.22^{\mathrm{a}}$ & $9.23^{\mathrm{a}}$ \\
\hline \begin{tabular}{|l|l|} 
Interaction Effects \\
\hline FOP * ONP
\end{tabular} & $2.34^{\mathrm{a}}$ & 0.10 & $4.84^{\mathrm{b}}$ \\
\hline FOP * NC & 0.61 & $3.13^{\mathrm{a}}$ & $4.50^{\mathrm{a}}$ & $1.88^{\mathrm{b}}$ \\
\hline ONP * NC & $4.49^{\mathrm{b}}$ & 1.02 & $2.63^{\mathrm{b}}$ & 0.41 \\
\hline
\end{tabular}

Note: Numbers shown in the Table are univariate F-values for analyses of variance. Degrees of freedom for FOP are $(5,433), \mathrm{ONP}=(2,433), \mathrm{NC}=(1,433), \mathrm{FOP} * \mathrm{ONP}=(10,433), \mathrm{FOP} * \mathrm{NC}=(5,433), \mathrm{ONP} * \mathrm{NC}=(2,433)$. All 3way interactions are nonsignificant with the exception of Purchase intentions $[F(10,425)=1.86, p<.05$; see Fig. 5]

${ }^{\mathrm{a}} p<.01 ;{ }^{\mathrm{b}} p<.05 ;{ }^{\mathrm{c}} p<.10$

Fig. 2 Study 1a: Effects of alternative FOP systems across objective nutrition profile levels: overall perceptions of product healthfulness and calorie evaluations
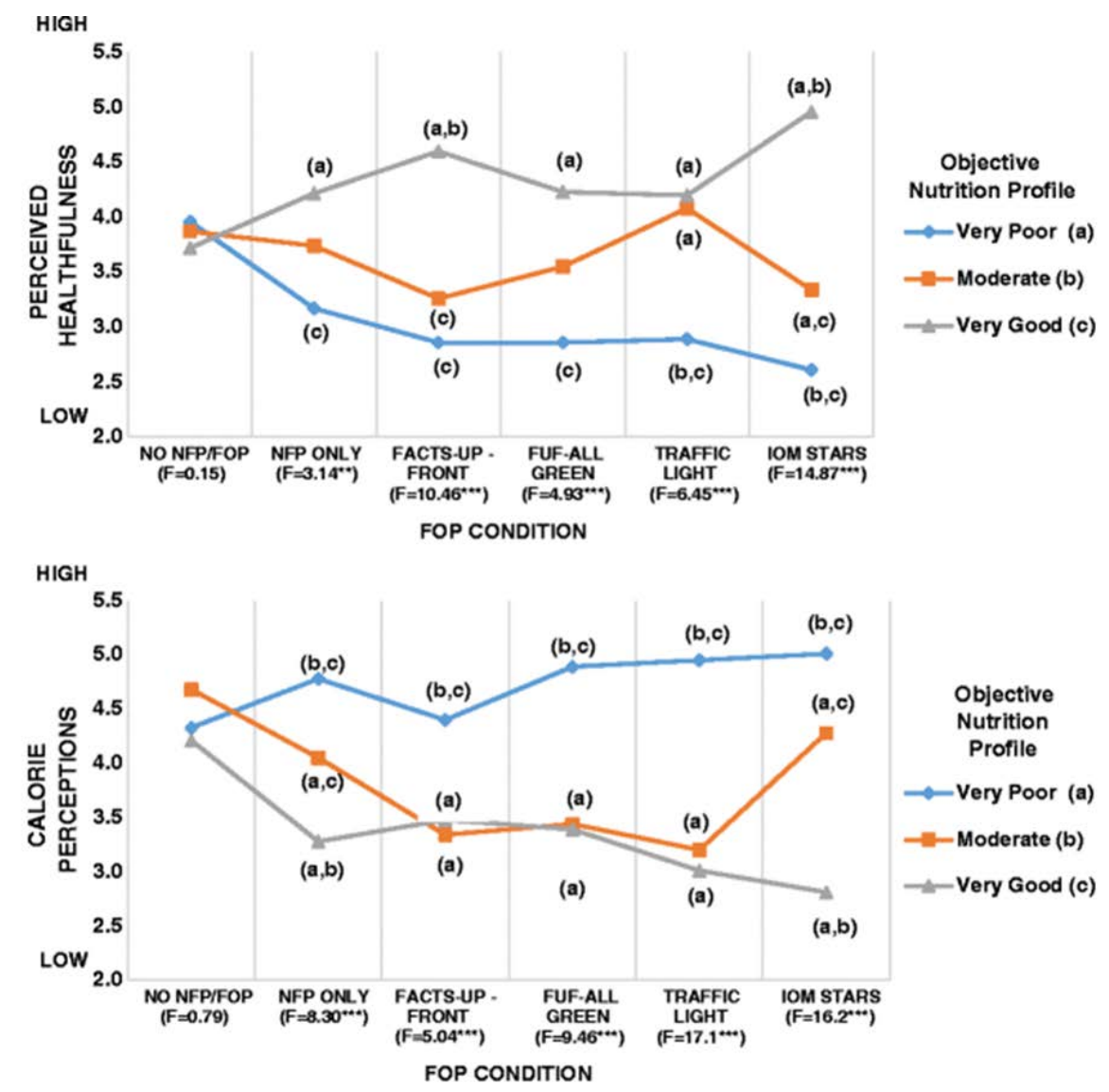

Note: Dependent measures all use 7 point scales. There was no nutrition information at all in the No NFP/FOP control condition, while there was NFP (but no FOP) information in the NFP Only condition. F-values shown below each FOP condition are results from interaction contrasts. The ${ }^{2, b r}$ superscripts are follow-up contrasts for differences in means between the three objective nutrition profile levels. For example, for the IOM Stars, the difference between the nutrition levels for perceived healthfulness is significant $(\mathrm{F}=14.87, p<.01)$, and the superscripts indicate that the perceived healthfulness of the Very Good objective level is significantly greater $(p<05$ or better) than the Moderate ('b') and Very Poor (' $a$ ') objective levels. The Very Poor level is significantly lower than the Moderate ( $(\mathrm{b})$ ) and Very Good ("c") levels.

${ }^{* *} p<01 ; * * p<05 ; " p<.10$. 
Relative to the controls, adding FOP information generally aids consumers in evaluating products with different objective nutrition profiles. As shown in Fig. 2, there are no differences across the profiles in the absence of nutrition information (full control condition). However, as the NFP and FOP information is made available, consumers perceive greater differences across the nutrition profiles.

For the plot of perceived healthfulness in the upper portion of Fig. 2, follow-up contrasts show that each of the nutrition disclosure conditions lead to significant differentiation across the three objective profiles. When there is no FOP nutrition information, the presence of the NFP leads to a significant difference between the Very Good (VG) and Very Poor (VP) objective profiles, but there are no differences between the Moderate (Mod) and the VG profiles, or the Mod and VP profiles. The plots and F-values show somewhat greater differentiation when the various FOP conditions are added to the package (all $p<.01$ ), but only the contrasts for the IOM stars format shows significant differences between each of the three respective objective levels (i.e., VG > Mod > VP).

Calorie perceptions are clearly important to both food marketers and consumers (Andrews et al. 2009; Chandon and Wansink 2007; IOM 2011; Feunekes et al. 2008). They are also interesting from an FOP labeling perspective because all systems tested here report calorie levels, but none offer any evaluative interpretation (i.e., no color coding and not considered as an input to the IOM star rating system). As shown for calorie perceptions in the bottom of Fig. 2, the FOP control (with the NFP available) differentiates between the objective profiles as well as the Facts-Up-Front format does. For three of the four FOP format conditions, there is little difference in calorie perceptions between the Moderate and VG levels. However, the plot and F-value ( $F=16.20 ; p<.001)$ suggest that the interpretive IOM stars again leads to differentiation between each of the three distinct objective levels. Saturated fat is also important to consumer health (CDC 2017) and to many consumers, and they are part of the FOP disclosures. The plot for the significant interaction $(p<.01)$ of FOP format and objective nutrition profiles is shown in Web Appendix Fig. 1 and again shows differentiation similar to that for calorie perceptions in Fig. 2.

\section{Effects on purchase intentions}

Results for purchase intentions are shown in the right-hand columns of Table 2 . Relative to the results for calories and nutrients, as might be expected, there is some attenuation in the strength of effects on purchase intentions. However, as predicted, the focal interaction between the FOP and these outcomes reaches significance $(p<.05)$ for both outcomes. The plot for purchase intentions is shown in Fig. 3. Follow-up analyses of variance show a significant effect of both the Traffic Light $(F(2431)=3.25$; $p<.05)$ and the IOM stars $(\mathrm{F}(2431)=9.29 ; p<.01)$ on purchase intentions across the three objective nutrition profile conditions. Both of these FOP formats are effective in reducing purchase intentions for the least objectively healthful product profiles. 


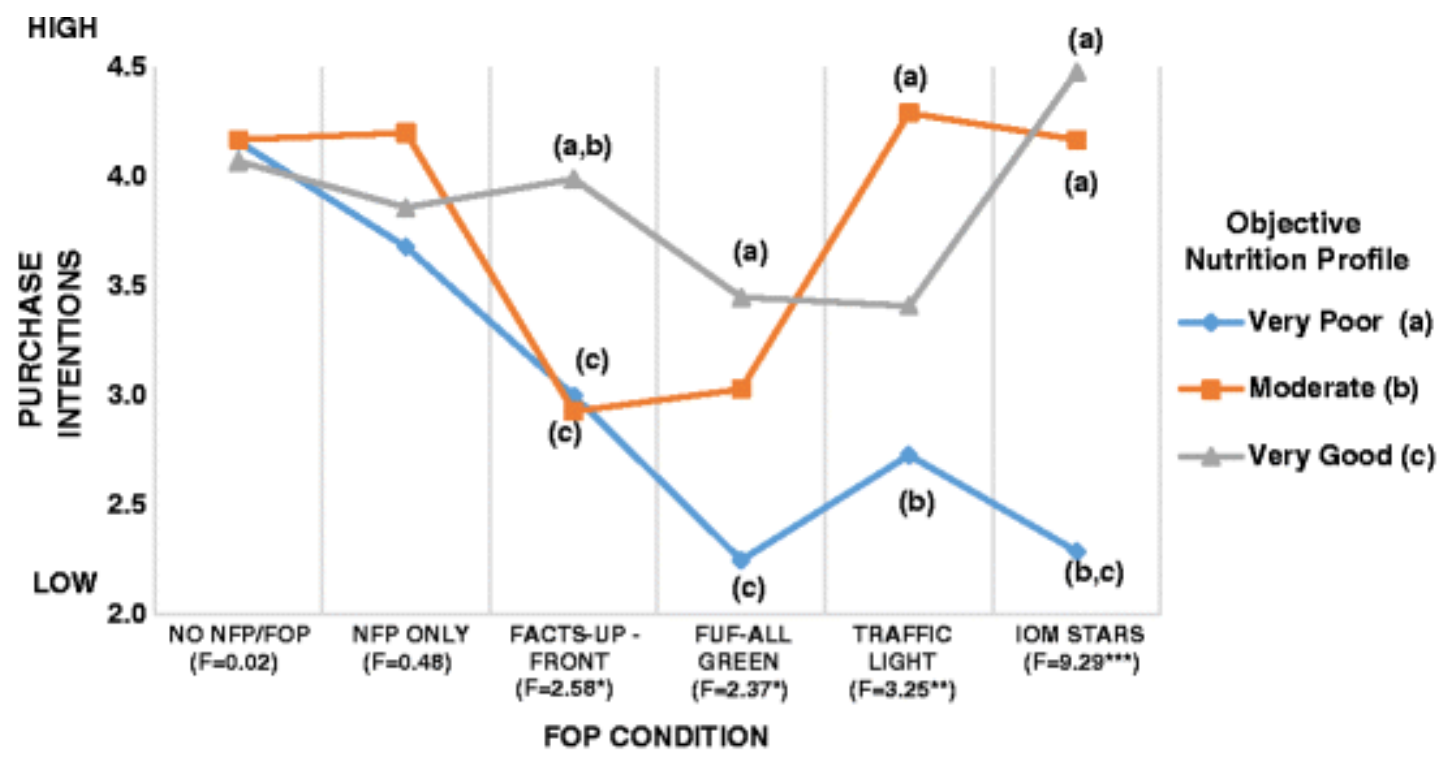

\begin{abstract}
Note: Dependent measures all use 7 point scales. There was no nutrition information at all in the No NFP/FOP control condition, while there was NFP (but no FOP) information in the NFP Only condition. F-values shown below each FOP condition are results from interaction contrasts. The ${ }^{2, b, c}$ superscripts are follow-up contrasts for differences in means between the three objective nutrition profile levels. For example, for the IOM Stars, the difference between the nutrition levels for intent is significant $(\mathrm{F}=9.29, p<01)$, and the superscripts indicate that the intent for the Very Good and Moderate objective levels are significantly greater $(p<.05$ or better) than the Very Poor level.

**** $p<.01 ;{ }^{* a 1} p<.05 ; * p<.10$.
\end{abstract}

Fig. 3 Study 1a: Effects of alternative FOP systems across objective nutrition profile levels on purchase intentions

In sum, these results support the premise that adding FOP information to a package can help consumers differentiate between products with differing objective nutrition profiles, relative to the NFP alone. In addition, there are differences based on the types of FOP labels used. ${ }^{4}$

\title{
Moderating role of nutrition consciousness on healthfulness and product evaluations
}

$\mathrm{H} 4$ focuses on the moderating role of nutrition consciousness (NC) on effects of the objective nutrition profiles on nutrient and product healthfulness evaluations. As shown in Table 1, NC interacts with the objective nutrition profile for product healthfulness and perceptions of calories and nutrients. A plot of the interaction for overall perceived healthfulness is shown in the upper portion of Fig. 4. The figure indicates there is a stronger effect on healthfulness perceptions for those higher $(F(1432)=25.89$; $p<.001)$ than lower $(F(1432)=5.18 ; p<.01)$ in NC. Consumers higher in NC differentiate between the VP $(M=2.60)$ and $\operatorname{Mod}(M=3.51)$ levels $(p<.01)$, as well as the between the VG $(M=4.27)$ and Mod $(\mathrm{M}=3.51)$ levels $(p<.01)$. In contrast, those lower in NC did not differentiate between the VP $(M=3.52)$ and $\operatorname{Mod}(M=3.78)$ levels $(p>.20)$, but perceived the VG objective profile as more healthful than the Mod and VP profiles ( $p<.05$ or better for each). The plot for calories is similar to this pattern. ${ }^{5}$ 


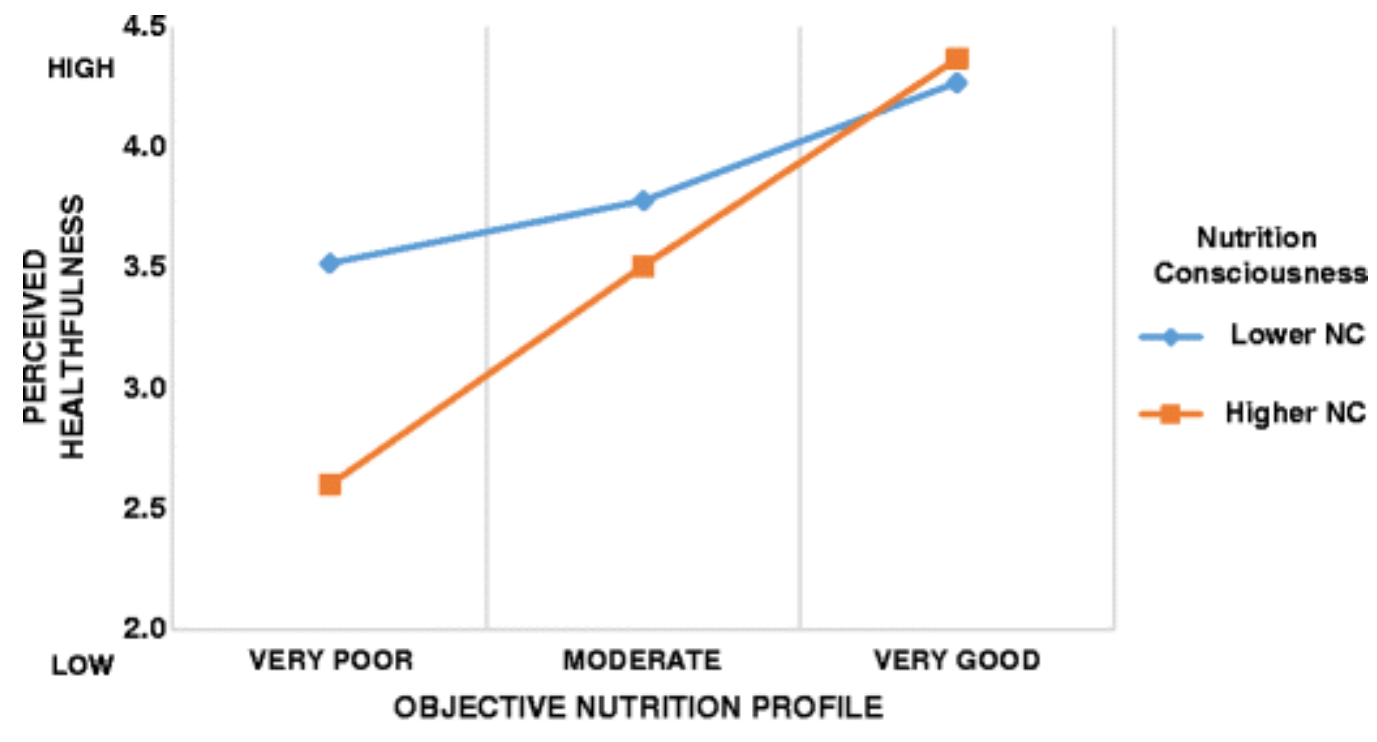

Note: Dependent measures all use 7 point scales.

Fig. 4 Study 1a: The moderating role of nutrition consciousness (nc) on effects of objective nutrition profile levels

The moderating role of nutrition consciousness across effects of the objective nutrition profile for the purchase intent did not reach significance (see Table 2). However, there was a three-way interaction $(p<.05)$. A plot of means is shown in Fig. 5. Probably the most interesting differences between those low and high in NC are shown for (1) the NFP present with no FOP condition and (2) the IOM stars condition. For those higher in NC, the NFP only (with no FOP disclosure) results in greater purchase intentions for the Mod or VG product compared to the VP product, while there is no difference $(F(2431)=0.54 ; p>.20)$ for those with lower NC (see Andrews et al. 2011). The IOM stars results in the only monotonic pattern of significant differences for purchase intentions (i.e., VG $>$ Mod $>V P$ ) for those high in NC. For those lower in NC, the evaluative IOM stars also has significant effects $(p<.05)$, but purchase intentions appear greatest for the product with the Moderate nutrition profile. This suggests that for this segment lower in NC, the importance of taste or other attributes may make the Very Good nutrition profile product somewhat less desirable. 

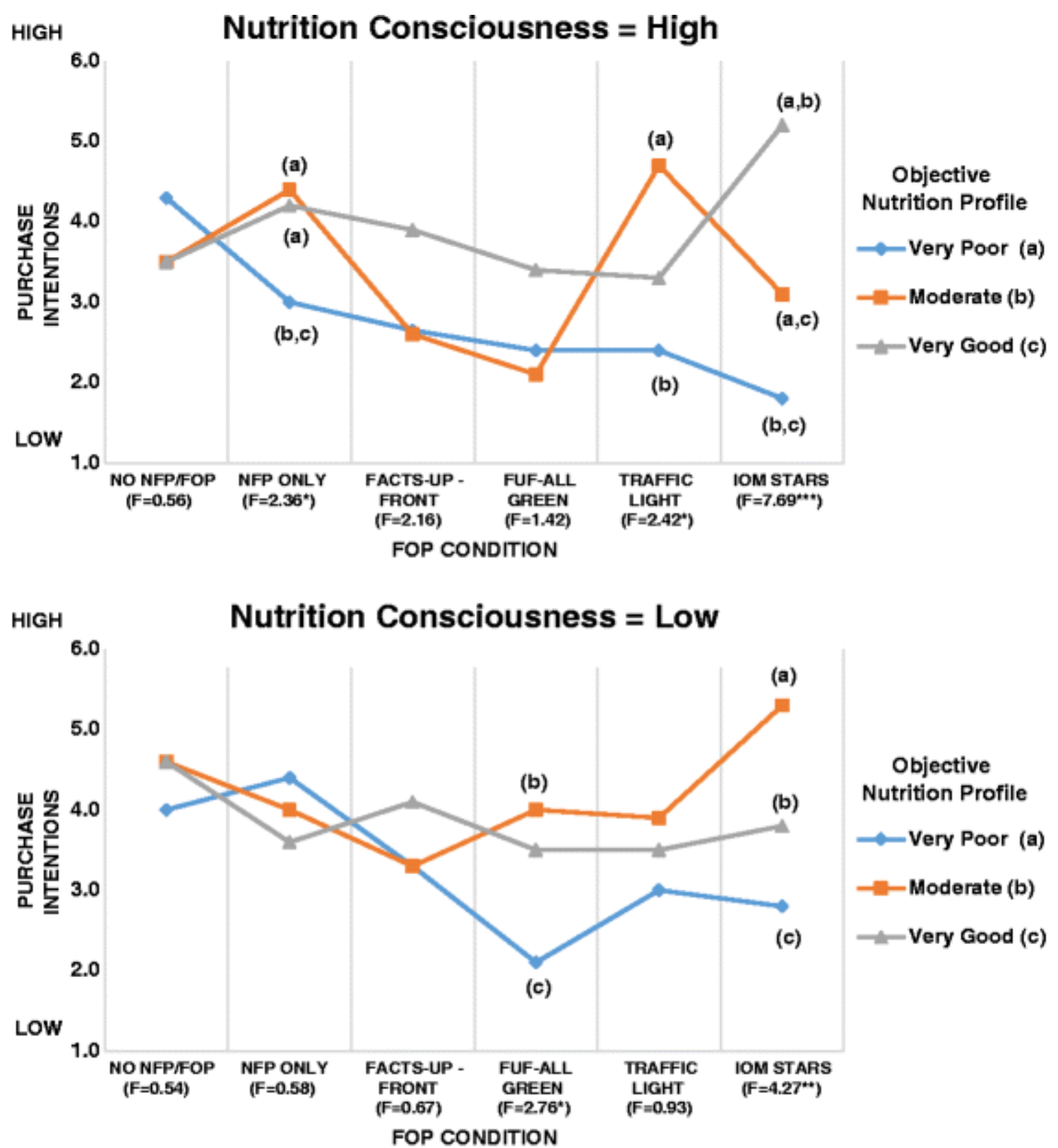

Note: Dependent measures all use 7 point scales. There was no nutrition information at all in the No NFP/FOP control condition, while there was NFP (but no FOP) information in the NFP Only condition. F-values shown below each FOP condition are results from interaction contrasts. The ${ }^{\mathrm{s}, \mathrm{b} f}$ superscripts are follow-up contrasts for differences in means between the three objective nutrition profile levels. For example, for the IOM Stars for high NC, the difference between the nutrition levels for intent is significant $(\mathrm{F}=7.69, p<.01)$, and the superscripts indicate that the intent for the Very Good and Moderate objective levels are significantly greater $(p<.05$ or better) than the Very Poor level.

t*m $p<.01 ;{ }^{\text {*** }} p<05 ;{ }^{*} p<10$.

Fig. 5 Study 1a: Effects on purchase intentions of the interaction of nutrition consciousness, FOP icon format, and objective nutrition profile levels

\section{Discussion}

In general, there is support for the predicted pattern of results as the nutrition and FOP icons are made available. In support of $\mathrm{H} 1 \mathrm{~b}$, when the NFP is accessed, it can generally be used by consumers to evaluate product healthfulness, relative to when no nutrition information is accessed at all (Keller et al. 1997; Mitra et al. 1999). The FOP by objective profile interaction for overall product healthfulness 
offers support for $\mathrm{H} 2$ As shown in the upper portion of Fig. 2, adding specific types of FOP information beyond the NFP Only condition aids consumers in determining product healthfulness. Importantly, the moderating role of FOP icons also extends to purchase intentions and disease risk. As shown in Fig. 3 for purchase intentions, there are significant differences indicated between the VG and the VP objective profiles when each of the FOP conditions is added to the package. Note that Fig. 3 suggests somewhat stronger results for the combined reductive-evaluative information disclosure (Traffic light) and evaluative disclosure (IOM stars) than the reductive-only disclosure (Facts-Up-Front). The IOM stars icon appears to be particularly useful in motivating differences in purchase intentions across the VG and the VP objective nutrition profiles (i.e., with a mean difference of more than two scale points $[p<.01])$, but there is little differentiation between the Mod and VG levels. The overall summary product evaluation and large perceptual difference indicated between the VG and VP products may lead to these differences that exceed those of the other FOP conditions.

In can be argued from a public health and consumer welfare perspective that differentiation between very good and very poor nutrition levels (as examined in Study 1a) are the situations in which FOP information is most beneficial to consumers. That is, it is critical for FOP information to assist consumers in distinguishing very healthful products from those that are very unhealthful (Federal Register 2010). However, these large differences between VG and VP nutrition profiles may also increase the likelihood that FOP by objective nutrition interactions emerge. As such, it can be argued that they provide a relatively liberal test of FOP effects.

Therefore, Study $1 \mathrm{~b}$ offers a somewhat more conservative test in which the differences between the more and less favorable objective profiles are less dramatic. Specifically, we partially replicate and extend our Study 1a findings by examining products that are moderate and equal in their levels of sugar and sodium, but differ in calories, fat, and saturated fat. This similarity in sugar and sodium affects the combined reductive/evaluative and evaluative-only label formats (traffic light and IOM star icons, respectively) because it (1) introduces the moderate "yellow" color coding into the traffic light for these nutrients and (2) reduces the number of stars in the IOM format. However, substantial variations in calories, fat, and saturated fat across the objective profiles remain.

\section{Study $1 b$}

\section{Methods}

\section{Design}

We again conducted a 6 (Front of Package nutrition format) $\times 3$ (objective product nutrition profile) $\times 2$ (consumer nutrition consciousness) between-subjects experiment. The six FOP format conditions were the same as those used in Study 1a (see Web Appendix A2). The product nutrition profile conditions were manipulated by altering the nutrient levels for calories, fat, and saturated fat, but the levels of sodium and sugar found in the NFP (and FOP where applicable) were moderate and held constant across the three objective nutrition profiles (see Web Appendix D). As shown in the NFPs in Web Appendix D, the fat and saturated fat levels ranged up to $50 \%$ of the daily value in the "Poor" condition, were reduced to $18 \%$ in the "Moderate" condition (a level that mirrored Study 1a), and fell to under $10 \%$ or below in the "Good" condition. The evaluative FOP formats reflected the consistent, moderate levels of sodium and sugar across conditions. In the traffic light FOP format, the levels of both sodium and sugars were "yellow" across all three nutrition profile conditions (instead of red or green), and all profiles received either one or two stars in the IOM evaluative FOP. Thus, compared to 
Study $1 a$, there were smaller differences between the three objective nutrition profiles reflected in the evaluative FOP formats (because sugar and sodium were constant), even though there was a substantial difference in the nutrition criteria of calories, fat, and saturated fat across the conditions.

\section{Sample, procedure, and dependent measures}

The sample consisted of 461 participants recruited from Amazon MTurk and ranged in age from 20 to 73 (mean = 37 years). Slightly more than half of the sample was female ( $55 \%$ female; $45 \%$ male), and the median income was $\$ 35-\$ 50,000$. As in Study 1 a, nutrition consciousness was a measured variable; coefficient alpha for the three-item measure was .91. Given the $6 \times 3$ design, a median split for the three items was again performed and the measure was recoded to reflect a low or high level of enduring nutrition consciousness. All dependent measures were identical to Study $1 \mathrm{a}$ and are shown in Web Appendix C.

\section{Results}

We performed an initial data check to assess if the FOP format influenced participants' interest in examining the NFP. Examination of the NFP ranged from $82 \%$ to $94 \%$, and was nonsignificant across FOP conditions $\left(\chi^{2}(5)=9.36 ; p>.10\right)$. The objective nutrition profiles showed significant differences $(F=14.66 ; p<.001)$ between the three profiles on the single-item healthiness measure. All contrasts between means were significant (all $p<.01$ ), with the mean for the more favorable nutrition profile greater than the moderate profile, and the less favorable profile lower than the moderate profile.

We performed analyses to assess the effects for the effects of any FOP information compared against (1) the NFP Only condition and (2) the full control where there is no nutrition information available. The multivariate interaction between the nutrition information conditions and the three objective profile conditions was significant (Wilks $\lambda=.85 ; \mathrm{F}=2.01 ;<.01$ ). In follow-up contrasts, when any of the FOP information was available, the differences across the three objective nutrition profiles reached significance for all four dependent measures (all F $>9.8 ; p<.01$ ). For the NFP only (i.e., no FOP) condition, the differences between the objective profiles were significant for calorie $(p<.05)$, saturated fat $(p<.01)$, and overall healthfulness evaluations $(p<.05)$, but not for purchase intent. As expected, in the full control (i.e., no nutrition information at all) condition, there were no significant differences. These results again show that FOP information disclosures have an effect beyond the NFP alone, yet the NFP by itself can be at least somewhat useful in evaluations of nutrient content.

Table 3 shows the moderating role of the specific FOP labeling systems on perceived calories, saturated fat, and purchase intention across the three objective nutrition profiles. As in Study 1a, findings provide support for a moderating role of the FOP systems across the objective profiles. Significant interactions (all $p<.01$ ) for two of the three healthfulness and nutrition measures were found. Plots for calorie perceptions and saturated fat are shown in Web Appendix Fig. 2, and reveal that the FOP conditions increased the ratings for the Poor nutrition profile condition (i.e., higher means indicate higher calorie/saturated fat level evaluations and are thus unfavorable). ${ }^{6}$

Table 3 Study 1b: Effects of front-of-package nutrition information, objective nutrition profile, and nutrition consciousness on healthfulness and purchase intention

\begin{tabular}{|l|l|l|l|l|}
\hline ANOVA Results & $\begin{array}{l}\text { Overall Perceived } \\
\text { Healthfulness }\end{array}$ & $\begin{array}{l}\text { Calorie } \\
\text { Evaluations }\end{array}$ & $\begin{array}{l}\text { Saturated Fat } \\
\text { Evaluations }\end{array}$ & $\begin{array}{l}\text { Purchase } \\
\text { Intentions }\end{array}$ \\
\hline $\begin{array}{l}\text { Independent } \\
\text { Mariables }\end{array}$ & & & \\
\hline
\end{tabular}




\begin{tabular}{|l|l|l|l|l|}
\hline $\begin{array}{c}\text { Front of Package } \\
\text { Icon (FOP) }\end{array}$ & 1.25 & $8.53^{\mathrm{a}}$ & $5.02^{\mathrm{a}}$ & 1.59 \\
\hline $\begin{array}{c}\text { Objective Nutrition } \\
\text { Profile (ONP) } \\
\begin{array}{c}\text { Nutrition } \\
\text { Consciousness (NC) }\end{array}\end{array}$ & $15.67^{\mathrm{a}}$ & $38.80^{\mathrm{a}}$ & $49.82^{\mathrm{a}}$ & $10.07^{\mathrm{a}}$ \\
\hline \begin{tabular}{|l|l|} 
Interaction Effects \\
\hline FOP * ONP
\end{tabular} & 1.45 & 0.76 & 0.86 & $141^{\mathrm{a}}$ \\
\hline FOP * NC & 0.45 & $3.33^{\mathrm{a}}$ & $3.65^{\mathrm{a}}$ & $1.75^{\mathrm{c}}$ \\
\hline ONP * NC & 0.88 & 1.10 & 1.03 & 1.63 \\
\hline
\end{tabular}

Note: Numbers shown in the Table are univariate F-values for analyses of variance. Degrees of freedom for FOP are $(5,425), \mathrm{ONP}=(2,425), \mathrm{NC}=(1,425), \mathrm{FOP} * \mathrm{ONP}=(10,425), \mathrm{FOP} * \mathrm{NC}=(5,425), \mathrm{ONP} * \mathrm{NC}=(2,425)$. All 3way interactions are nonsignificant with the exception of Purchase intentions $[F(10,425)=2.17, p=.016]$ ${ }^{\mathrm{a}} p<.01 ;{ }^{\mathrm{b}} p<.05 ;{ }^{\mathrm{c}} p<.10$

The moderating role of the FOP format also led to a significant three-way interaction for purchase intentions that extended the two-way interactions involving nutrition consciousness (NC). The purchase intentions of those high in $N C(F(2425)=2.93 ; p<.05)$ differed between the products based on the provision of the NFP alone, while there was no difference at all for those lower in NC $(F(2425)=0.03 ; p>.80)$. For example, the means for the Poor product were 2.06 for those high in NC compared to $3.93(p<.01)$ for those low in NC. The means for the Good product increased to 3.71 for those high in NC, while they remained relatively consistent at 4.08 for those low in NC.

The Traffic Light appeared to help with the interpretation for those lower in NC, while the IOM stars icon was of little help. The traffic light also produced differences for the consumers high in NC, but the Moderate product yielded results somewhat more favorable than the Good product (Recall that the attributes of sodium and sugar were always consistent at an intermediate level and were yellow in the traffic light condition. These nutrients may be of somewhat lesser importance than other nutrients and calories for those low in NC). For those high in NC, the IOM stars, which are similar between the Moderate and Good objective nutrition profiles in this study, resulted in no differences in purchase intentions for these products ( $\mathrm{M}_{\mathrm{Good}}=3.83 \mathrm{vs}$. $\mathrm{M}_{\mathrm{Mod}}=3.18$ ), but intentions for the Good product exceeded those for the Poor product (Mpoor $=2.46 ; p<.05)$.

$\mathrm{H} 4$ concerns the moderating impact of nutrition consciousness on effects of the objective nutrition profile on nutrient and overall product healthfulness. As shown in Table 3, there was little moderating effect of NC when the profiles were more similar, relative to Study 1 .

\section{Discussion}

The pattern of findings shows a consistent moderating role for the FOP format manipulation on evaluations of calories and nutrients (the specific information most easily gleaned or inferred from the FOP disclosures). However, in contrast to Study 1a, these moderating FOP disclosure effects generally do not extend to the broader evaluation measures of purchase intentions. Thus, as the differences in the objective profiles narrowed, there was less impact on intentions. Yet, effects of the icons remain for many of the differences in perceptions and intentions when comparing only the Poor and Good objective profiles. Generally, while the evaluative IOM stars icon had a strong effect in Study 1a, these effects were consistent or were exceeded by the reductive Facts-Up-Front icon in Study $1 b$. This is 
likely due to the fact that the moderate level of sodium and sugars, both of which are components of the 0-3 star evaluative rating system, did not reach the qualifying level for "low."

Studies $1 \mathrm{a}$ and $1 \mathrm{~b}$ addressed the effects of a large array of FOP formats on a single product that differed in nutrition profiles. However, consumers often examine multiple alternatives in retail environments, evaluate their healthfulness, and ultimately choose a relatively healthful option that will improve their overall diet (NLEA 1990). In such retail contexts, consumers must simultaneously evaluate a product relative to the other products that are present in a category. This task is often considerably more cognitively challenging than evaluating a single product in isolation (e.g., van Horen and Pieters 2012; Newman et al. 2016). Thus, we extend our results to a retail lab in Studies 2 and 3, where consumers examined multiple products in a comparative choice set context.

\section{Study 2}

\section{Methods}

\section{Design}

To assess the effects of prominent evaluative and reductive FOP icons on healthfulness perceptions within a set of products, we conducted a 3 (Front of Package nutrition format: evaluative IOM stars icon vs. reductive Facts-Up-Front icon vs. NFP only control) $\times 3$ (objective nutrition profile: more nutritious [Good] vs. moderate vs. less nutritious [Poor]) mixed experimental design. Participants were randomly assigned to one of the three nutrition format conditions, while the objective nutrition profiles for the three products in the category set served as the repeated measure. Consumer nutrition consciousness was again a measured independent variable.

Research was conducted in a lab facility designed to look like a retail store with a wide variety of products (e.g., food, DVDs, beauty supplies) and arrangements (e.g., aisles, endcaps, islands) (see Web Appendix E). Participants were presented with a set of three cereal products (for a single family brand; see Web Appendix E) with varying objective nutrition levels on a shelf. One cereal was pre-designated as objectively more nutritious based on its qualification for three IOM stars, while the other two cereals were designated as moderate and less nutritious based on their qualification for 1 star and 0 stars, respectively. The order of the products on the retail shelf was counterbalanced.

The FOP conditions used were consistent with the Facts-Up-Front (FUF) reductive and evaluative IOM stars icons in Studies $1 \mathrm{a}$ and 1b, and appeared on the front of the cereal packages (when appropriate). Neither icon appeared on any packages in the FOP control condition. The NFPs were available on the back of the packages to all participants at all times, and the nutrition levels presented in the icons were identical to those shown in the NFP for each product. The distribution of the stars in the evaluative icon was again based on the IOM standards.

\section{Sample, procedure, and dependent measures}

Participants filled out a questionnaire about the cereal products at the retail shelf. They indicated their healthfulness perceptions of all three cereals by replying to measures similar to those used in Studies $1 \mathrm{a}$ and $1 \mathrm{~b}$. Healthfulness perceptions were assessed for each product separately by the statement "Please consider the nutrition level of Do you believe that this item is:" with anchors of "not at all nutritious" /"highly nutritious" and "very unhealthy" /"very healthy" (Newman et al. 2014; all $r>$.87, all $p<.001$ ). Also similar to Studies $1 a$ and $1 b$, nutrition consciousness was measured rather than 
manipulated using the item, "In general, how interested are you in reading nutrition and health-related information?" with anchors of "not interested"/ "very interested." Given the repeated measure design and consistent with Studies $1 \mathrm{a}$ and $1 \mathrm{~b}$, a median split was again performed to create groups of higher and lower nutrition consciousness. After reporting their healthfulness evaluations in the retail lab, participants were escorted to a nearby computer lab where they responded to the manipulation check, $\mathrm{NC}$ measure, and demographics in a concluding online survey. Subjects were recruited from a large university's research subject pool and were compensated for their participation. The mixed sample consisted of 82 participants ranging in age from 19 to 45 ; approximately $59 \%$ of participants were male.

\section{Results}

\section{Manipulation check}

To check the FOP icon manipulation, a picture of each icon was shown separately and participants were asked the following for each icon: "Refer to the picture above. Did you see this nutrition icon?" with responses of "no" and "yes." One hundred percent of participants correctly indicated seeing the evaluative icon when it was present, $96 \%$ correctly indicated seeing the reductive icon when present, and $94 \%$ in the control condition indicated that they did not see either icon (all $p<.001$ ).

\section{Effects on perceived healthfulness of the products}

A primary objective of Study 2 was to assess whether consumers can use different types of FOP icons to distinguish more nutritious products from less nutritious products. We conducted a repeated measures analysis for the effects of the FOP manipulation and NC on healthfulness perceptions of the Good, Moderate, and Poor objective profiles. Results show that the overall 3-way FOP format $x$ objective nutrition profile $x$ NC interaction did not reach significance $(p>.20)$. However, many of the follow-up contrasts of interest were significant, as well as the FOP format $x$ nutrition profile interaction $(F(4152)=5.51 ; p<.001)$. A plot of the means for the three factor design on healthfulness perceptions is offered in Fig. 6. 


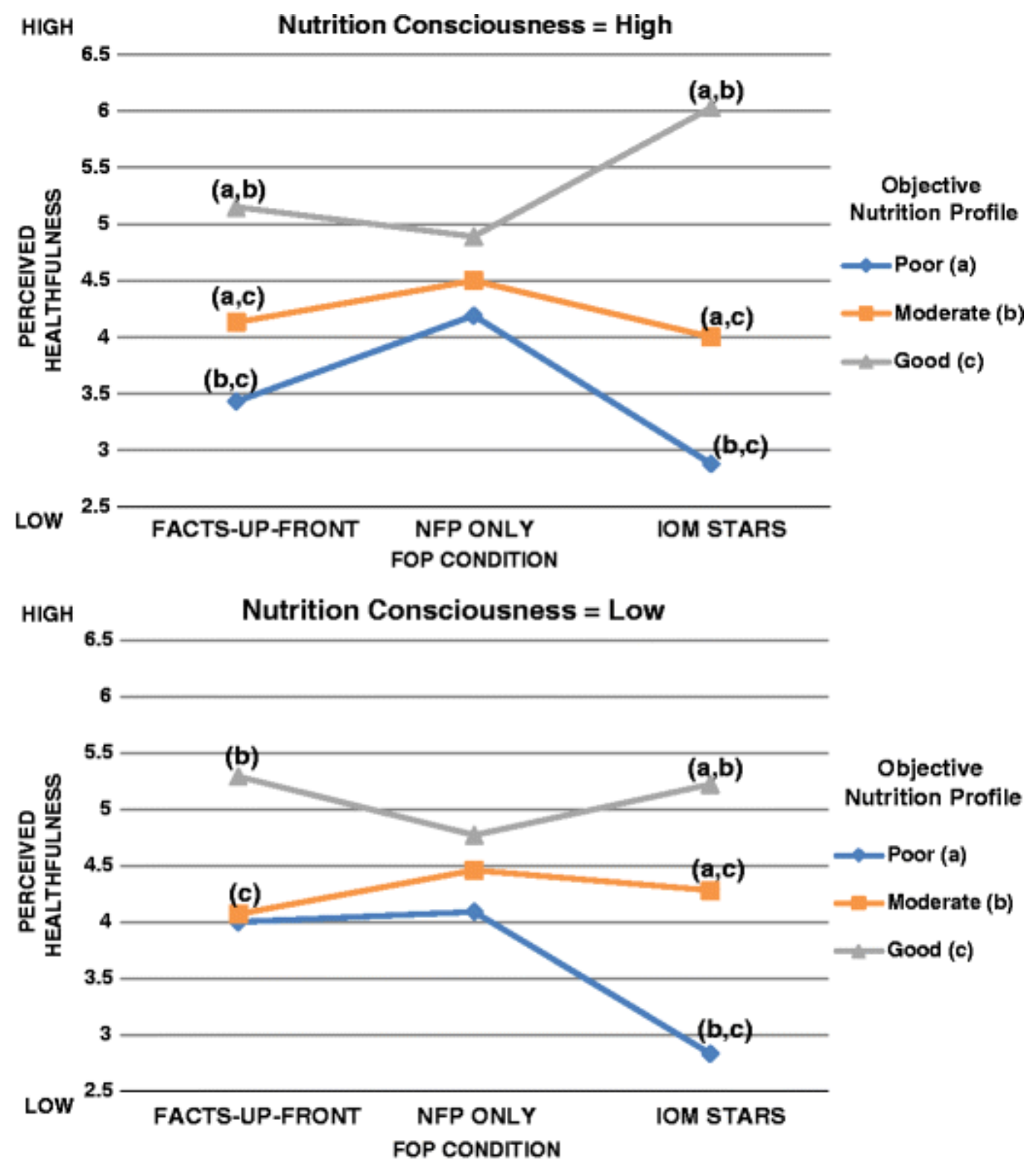

Note: Dependent measures all use 7-point scales. The ${ }^{x, b, c}$ superscripts are contrasts for differences in means between the three objective nutrition profile levels. For example, for the IOM Stars when NC is high, the difference in perceived healthfulness is significant, and the superscripts indicate that the perception of healthfulness for the Good and Moderate objective levels are significantly greater ( $p<.05$ or better) than the Poor level. In addition, the 'Good' level is significantly greater than the 'Moderate' level.$$
* * * p<.01 ;{ }^{* *} p<.05 ;{ }^{*} p<10 .
$$

Fig. 6 Study 2 Effects on overall perceived healthfulness of the interaction of nutrition consciousness, FOP icon format, and objective nutrition profile level

As shown in the top portion of Fig. 6, when no FOP information was available, there were no perceived healthfulness differences between the objectively Good, Moderate, and Poor products among those high in NC $(F(2,75)=1.32 ; p>$. 20 and all $p$-values for contrasts between objective nutrition levels range from .11 to .41). However, the provision of the evaluative IOM stars led to significant differences in healthfulness perceptions among the high NC group $(F(2,75)=27.38 ; p<.001)$. Contrasts reveal significant differences between the objectively Good nutrition product $(M=6.03)$ and both the Poor $(M=2.88 ; p<.001)$ and Moderate products $(M=4.00 ; p<.001)$ for the high NC participants. The presence of the stars also led to a significant difference between the Poor $(M=2.88)$ and Moderate item $(M=4.00 ; p<.01)$. 
As further shown in the top portion of Fig. 6, the provision of the reductive FUF icon also led to significant, yet less pronounced, differences in healthfulness perceptions for those high in NC $(F(2,75)=9.27 ; p<.001)$. Specifically, the Good $(M=5.15)$ product was viewed as more healthy than both the Poor $(M=3.43 ; p<.001)$ and Moderate product $(M=4.13 ; p<.01)$. The FUF icon also led to a significant difference between the Moderate and Poor nutrition items $(p<.05)$.

As could be expected, these results suggest that consumers who are high in NC can effectively use both the evaluative or reductive FOP icon to identify and differentiate objectively more nutritious products from moderate and less nutritious products. However, recall that this multiple product, comparative task is more complex and cognitively challenging than evaluating just a single food product in isolation (van Horen and Pieters 2012). Accordingly, when faced with evaluating multiple products at once, we expect that lower NC consumers will likely find the evaluative IOM stars icon more helpful than the quantitative FUF icon.

As shown in the bottom portion of Fig. 6, for those low in NC, there were no perceived healthfulness differences between the objectively Good, Moderate, and Poor products in the no FOP information control condition $(F(2,75)=.75, p>.45$; all $p$-values for contrasts range from .22 to .46). Similarly, the provision of the reductive FUF icon did not lead to significant differences in perceived healthfulness, overall, for the low NC group $(\mathrm{F}(2,75)=2.79 ; p=.07)$. Contrasts reveal that the reductive FUF icon did not allow those low in NC to effectively distinguish between the Poor and Moderate items $(p>.90)$. However, as suggested by the plot, the FUF reductive icon did lead to at least some differentiation between the Good $(M=5.29)$ and both the Moderate $(M=4.07)$ and Poor products $(M=4.00$; all $p<.10$ or better for both).

On the other hand, the provision of the evaluative IOM stars led to significant differences in healthfulness perceptions among all three products for the low NC participants $(F(2,75)=7.57$, $p<.001)$. Specifically, contrasts for the differences between the Good $(M=5.22)$ and both the Poor $(\mathrm{M}=2.83 ; p<.001)$ and Moderate items $(\mathrm{M}=4.28 ; p<.05)$ were all significant. The presence of the stars additionally led to a significant difference between the Poor and Moderate products $(p<.01)$. Thus, the evaluative FOP icon was the only format that allowed low NC participants to accurately discriminate between all 3 levels of objective product healthfulness.

\section{Discussion}

Study 2 showed initial results for two primary FOP formats (evaluative vs. reductive) in a comparative context in which participants evaluated three products on a retail shelf at once. In Study 3 , findings again show benefits of the FOP icons relative to the control conditions. Results across differing levels of nutritious consciousness further indicate that those with high NC could use either the evaluative IOM stars or reductive FUF icon to accurately differentiate between objectively Good, Moderate, and Poor nutrition products in a choice set. By contrast, those with low NC could use the evaluative IOM stars to differentiate between the healthfulness of all three products, but failed to fully distinguish between some items using the reductive FUF icon. Overall, these findings support the premise that evaluative FOP icons generally allow consumers to better assess the healthfulness of multiple food products in a set than do reductive FOP icons (which provide specific and quantitative, but less interpretive, information). This seems particularly true for lower NC consumers.

Because a primary purpose of nutrition information on packages is to encourage consumers to make "more informed and healthier food choices" (Federal Register 2010), understanding the role of FOP disclosures in improving the healthfulness of choices from a large set of products (as commonly 
encountered in a grocery store) is a critical concern. Thus, Study 3 extends the Study 2 results to an even more challenging choice setting in which nine products in a category are presented at the retail shelf. Here, a key objective is to examine the role of healthfulness perceptions as a potential mediator of consumers' intentions to purchase an objectively more nutritious product from a larger choice set consisting of products of varying healthfulness. Because healthfulness is an important attribute positively related to purchase intentions (Burton et al. 2015; Nielsen 2015), it should serve to mediate effects from even a large choice set. Study 3 also extends Study 2 findings by assessing whether an increase in FOP nutrition information assists consumers as the complexity of their choice environment increases. Specifically, we use a new experimental design to determine whether including both types of icons together on the FOP (evaluative and reductive) has an incremental positive effect on consumers' purchase intentions for a more healthful product beyond that afforded by an evaluative FOP icon alone.

\section{Study 3}

\section{Methods}

Study 3 was a 2 (evaluative FOP icon: IOM stars present vs. control) $\times 2$ (reductive FOP icon: Facts-UpFront present vs. control) between-subjects experimental design. Participants were randomly assigned to one of the four icon conditions. Nine granola bars were chosen as the focal category to increase the generalizability of our results, and to again be consistent with prior research that used nutritionallymixed products (e.g., Andrews et al. 2011). The FOP icons used here were the same as those utilized in Study 2; neither icon appeared on any packages in the control condition. The NFPs were again available on the back of the packages to all participants at all times, and the nutrition levels presented in the icons were identical to those in the NFP for each product. The number of stars in the evaluative icon was again based on the IOM's standards.

The data collection was conducted in the same retail lab facility as Study 2 (see Web Appendix E). Participants were presented with a set of nine boxes of granola bars of varying objective nutrition levels on a shelf in the lab. Three product options were pre-designated as Good nutrition options based on their qualification for 3 stars according to the IOM's criteria, while three were considered Moderate ( 1 or 2 stars) and the remaining three were considered Poor (0 stars). The order of the products was counterbalanced on the shelf to control for possible positioning confounds.

Subjects were recruited from a large university's research subject pool and were compensated for their participation. The sample consisted of 100 participants ranging in age from 18 to 43, and approximately $56 \%$ of participants were female. Purchase intentions for one of the objectively nutritious (3-star) focal granola bars was measured using the item "Assuming you were interested in purchasing this type of food, how likely are you to buy given the information shown on the package?" with anchors of "very unlikely" /very likely" and "not probable" /"very probable" $(r=.98$, $p<.001$; Newman et al. 2014). Healthfulness perceptions were measured using the same items utilized in Study $2(r=.86 p<.001)$. 


\section{Results}

\section{Manipulation check}

The same check from Study 2 was used to assess the manipulation of the FOP icons. Cross tabulations indicated high awareness of both the evaluative icon $\left(\chi^{2}=104.00 ; p<.001\right)$ and reductive icon $\left(\chi^{2}=68.98 ; p<.001\right) .100 \%$ of respondents correctly indicated seeing the evaluative icon when it was present, while $97 \%$ correctly indicated seeing the reductive icon when it was present.

\section{The mediating effect of perceived product healthfulness}

To examine the potential mediating role of perceived healthfulness within a large comparative choice set (consisting of nine items), we performed a conditional mediation analysis (Hayes 2013; Model 8) for the dependent variable of purchase intentions for the pre-designated objectively Good granola bar product. Based on our conceptualization and the results of our prior studies, we expect the interpretive component of the evaluative FOP icon to become more beneficial as the task of considering multiple products becomes more complex. The conditional mediation analysis allows us to further examine whether presenting both types of icons together on a package (evaluative and reductive) is more beneficial than offering only the evaluative icon, alone. An overview of the mediation results is shown in Table 4.

Table 4

Study 3: Effects of FOP icon types and perceived healthfulness on purchase intentions for an objectively nutritious product

\begin{tabular}{|c|c|c|c|c|c|c|}
\hline & \multicolumn{3}{|l|}{ Model 1} & \multicolumn{3}{|l|}{ Model 2} \\
\hline & $\begin{array}{l}\text { Regression } \\
\text { Coefficient }\end{array}$ & $\begin{array}{l}t- \\
\text { value }\end{array}$ & $\begin{array}{l}p- \\
\text { value }\end{array}$ & $\begin{array}{l}\text { Regression } \\
\text { Coefficient }\end{array}$ & $\begin{array}{l}t- \\
\text { value }\end{array}$ & $\begin{array}{l}p \text { - } \\
\text { value }\end{array}$ \\
\hline \multicolumn{7}{|l|}{ Icon Types } \\
\hline $\begin{array}{l}\text { Reductive /Facts-Up- } \\
\text { Front (FUF) }\end{array}$ & .81 & 2.09 & $<.05$ & .54 & 1.39 & $>.10$ \\
\hline Evaluative (Stars) & 1.17 & 3.08 & $<.01$ & .91 & 2.38 & $<.02$ \\
\hline FUF $*$ Stars & -.38 & 0.77 & $>.20$ & -.11 & 0.14 & $>.20$ \\
\hline \multicolumn{7}{|l|}{ Mediator: } \\
\hline $\begin{array}{c}\text { Perceived } \\
\text { Healthfulness }\end{array}$ & - & - & - & .43 & 2.79 & $<.01$ \\
\hline
\end{tabular}

Note: The dependent variable is the purchase intentions for one of the objectively more nutritious products in the category set. The conditional mediation tests show that the stars $\rightarrow$ healthfulness $\rightarrow$ purchase intentions is positive and significant (indirect effect $=.39, \mathrm{Cl}[.08, .89]$ ) in the absence of the reductive Facts-Up-Front icon. However, this same mediation effect becomes nonsignificant when the Facts-Up-Front icon is added to the front of the package (indirect effect $=.13, \mathrm{Cl}[-.16, .54]$ ), as indicated by the inclusion of zero in the confidence interval

Model 1 in Table 4 shows effects of the icon manipulations without the mediator (perceived healthfulness of the objectively Good focal product) included. Both the evaluative icon ( $b=1.17$, $t=3.08 ; p<.01)$ and reductive icon $(b=.81, t=2.09 ; p<.05)$ have positive and significant effects on purchase intentions for the more nutritious Good focal product, while the interaction between icons is nonsignificant. Model 2 in Table 4 shows the effects when the mediator is included (Hayes 2013). The 
direct effects of the icons indicates that there is a significant positive effect of the evaluative IOM stars icon on purchase intentions $(b=.91, t=2.38 ; p<.02)$, but that the reductive FUF icon does not reach significance $(b=.54, t=1.39 ; p>.10)$. The interaction between icons again is nonsignificant $(p>.20)$, and the proposed mediator of perceived healthfulness has a significant effect on purchase intentions $(b=.43, t=2.79 ; p<.01)$.

In tests of the mediation, the indirect effect (IE) for the stars $\rightarrow$ healthfulness $\rightarrow$ purchase intentions mediational path is positive and significant $(\mathrm{IE}=.39, \mathrm{Cl}[.08, .89])$ when the reductive FUF icon is not included on the packages (i.e., when the stars are presented alone). However, this same IE of the evaluative icon through perceived healthfulness becomes nonsignificant when the FUF icon is also included on the packages (IE $=.13, \mathrm{Cl}[-.16, .54]$ ) (i.e., the confidence interval contains zero). This suggests that the cumulative effect of evaluative and reductive FOP information, together, reduces the IE on intentions to purchase the focal nutritious product (compared to the effect of evaluative FOP information, alone). ${ }^{7}$

These results further support the beneficial role of evaluative FOP icons for this more complex comparative task (but also again suggest that there are at least some benefits of either evaluative or reductive icons, separately). These findings also suggest that the presence of both types of icons on the FOP together (evaluative and reductive) does not benefit consumers beyond having only an evaluative FOP icon in more challenging choice settings. ${ }^{8}$

\section{General discussion}

Given the obesity health issue in the U.S. (CDC 2017), many food companies have responded by changing their communication efforts to more effectively convey nutrition information to consumers on food packages (e.g., Andrews et al. 2014; Wilkie and Moore 2012). Still, consumers have been confronted with a confusing array of FOP symbols and information, and there has been only limited experimental research assessing their effectiveness across both a broad range of icons and objective nutrition levels. It therefore has become increasingly important to examine a diverse set of icons and evaluations of calories and nutrients leading consumers to make more informed and healthier food choices in the context of their daily diet (NLEA 1990).

\section{Overview of findings and conceptual contributions}

Table 5 presents an overview of prior research and indicates how our current studies offer new conceptual and managerial insight. In Fig. 1, we proposed that there are perceptual characteristics that differ between the NFP and FOP icon formats that lead to differences in diagnosticity and usefulness in product evaluations. Compared to the more complex (and less accessible) NFP, we suggested that including reductive (i.e., quantitative) FOP information can generally aid consumers in evaluating the healthfulness of product alternatives. However, other FOP formats that provide even less complicated, evaluative information (e.g., IOM Stars) can potentially further increase perceived differences between more and less healthful products. Study 1a, which examined products with larger differences between more and less healthful options, showed general support for the proposed conceptual FOP hierarchical continuum. Results showed a FOP x objective nutrition profile interaction indicating that adding any type of FOP information aids consumers in determining perceived healthfulness beyond the "no nutrition information" and "NFP Only" conditions. Consistent with the conceptual differences in complexity and perceived diagnosticity relative to the NFP, all tested FOP formats appear to help differentiate between the most and least objectively healthful products (Fig. 2). Further, the 
differences in diagnosticity and complexity for FOP icons that offer an evaluative dimension (and in particular, the IOM Stars), seem to lead to somewhat more beneficial effects on purchase intentions (Fig. 3).

Table 5 Managerial insights from prior research, insights from the current studies, and opportunities for future research

\begin{tabular}{|c|c|c|}
\hline $\begin{array}{l}\text { Managerial Insights from } \\
\text { Previous Research }\end{array}$ & $\begin{array}{c}\text { New Managerial Insights from the } \\
\text { Current Research }\end{array}$ & Ideas for Future Research \\
\hline $\begin{array}{l}\text { Prior research has examined } \\
\text { numerous FOP icons (e.g., } \\
\text { Smart Choices, IOM Stars, } \\
\text { Traffic Lights, Facts Up Front) } \\
\text { in independent studies } \\
\text { (Pettigrew et al. 2017; Kees et } \\
\text { al. 2014; Graham et al. } \\
\text { Andrews et al. 2011; Newman } \\
\text { et al. 2016). Some findings } \\
\text { suggest that more simplistic } \\
\text { icons (e.g., dichotomous) are } \\
\text { most useful for consumers } \\
\text { when evaluating many } \\
\text { products in a realistic shopping } \\
\text { setting. Results also suggest } \\
\text { these icons present a market } \\
\text { environment that may } \\
\text { minimize risks (e.g., positive } \\
\text { cues only) for food } \\
\text { manufacturers. Yet, } \\
\text { dichotomous icons may be } \\
\text { misleading (e.g., Smart } \\
\text { Choices), and there are some } \\
\text { benefits of more detailed } \\
\text { nutrition icons. More complex } \\
\text { systems are most useful for } \\
\text { consumers when evaluating a } \\
\text { single product. }\end{array}$ & $\begin{array}{l}\text { The current research examined a } \\
\text { much larger set of FOP systems } \\
\text { than in previous studies. Results } \\
\text { suggests that FOP systems with } \\
\text { conceptual differences in } \\
\text { complexity and perceived } \\
\text { diagnosticity can have favorable } \\
\text { effects for consumers, but these } \\
\text { effects vary across contexts for } \\
\text { each system. While reductive } \\
\text { systems can be beneficial when } \\
\text { consumers have sufficient time, } \\
\text { motivation, and ability to evaluate } \\
\text { the FOP, managers should strongly } \\
\text { consider evaluative systems in } \\
\text { complex/challenging product } \\
\text { comparison settings such as retail } \\
\text { grocery stores where consumers } \\
\text { attempt to compare multiple } \\
\text { products under time pressure in } \\
\text { more difficult product evaluation } \\
\text { environments. }\end{array}$ & $\begin{array}{l}\text { Given the dynamic and } \\
\text { unregulated FOP } \\
\text { environment in most } \\
\text { countries, future studies } \\
\text { should test new systems that } \\
\text { further integrate reductive } \\
\text { and evaluative conceptual } \\
\text { components related to the } \\
\text { accessibility and diagnosticity } \\
\text { of existing FOP icons. Future } \\
\text { research should also examine } \\
\text { how various FOP systems } \\
\text { interact with other on- } \\
\text { package information such as } \\
\text { health claims and other } \\
\text { implied nutrition claims. }\end{array}$ \\
\hline $\begin{array}{l}\text { Prior research has shown that } \\
\text { product healthfulness can } \\
\text { moderate FOP system effects } \\
\text { (Newman et al. 2014; Newman } \\
\text { et al. 2016). Findings from } \\
\text { these studies find that the } \\
\text { presence of an FOP icon can } \\
\text { increase (decrease) purchase } \\
\text { intentions for healthy } \\
\text { (unhealthy) food options. FOP }\end{array}$ & $\begin{array}{l}\text { A broad set of nutrition profiles } \\
\text { were tested in the current } \\
\text { research. Prior research has not } \\
\text { considered such nuances related to } \\
\text { the differences in objective } \\
\text { nutrition levels of products. In } \\
\text { situations where competitive } \\
\text { products are similar in nutrition } \\
\text { profiles, managers who seek to } \\
\text { differentiate their products on }\end{array}$ & $\begin{array}{l}\text { Given the somewhat } \\
\text { subjective nature of } \\
\text { evaluative FOP systems, } \\
\text { more research is needed on } \\
\text { the role of believability of } \\
\text { FOP systems. Future studies } \\
\text { should study the role of } \\
\text { perceived credibility of FOP } \\
\text { systems (e.g., are certain FOP } \\
\text { icons perceived as "factual" }\end{array}$ \\
\hline
\end{tabular}


labeling systems can simultaneously empower a retailer to assist its customers with making healthier decisions, and also deliver value to the firm.

Most of the prior experimental research on FOP systems manipulate the type of FOP icon while holding other factors (e.g., product, brand, etc.) constant to isolate the effects of the specific FOP icon(s) tested (e.g., Biaklova et al. 2014; Kees et al. 2014). Some findings from this research show that the more complex GDA-style system can result in the highest levels of attention. However, a simpler FOP system could actually have more influence on consumer choice in a real shopping environment because consumers may stop processing the more complex icon once they realize that they would need to spend extra time and cognitive effort making sense and utilizing all the information.

Previous research has considered a variety of consumer and market variables that interact with nutrition information provision (e.g., Andrews et al. 2011; Dzhogleva and Inman 2015). Findings from this research show that nutrition consciousness can moderate effects related to consumer use of the back-of-package health characteristics may opt for reductive FOP systems. Evaluative FOP systems are more useful for consumers in distinguishing between very healthy/very unhealthy products.

As an extension to most previous studies which hold a single focal product constant while examining FOP systems, the current research examined the role of FOP systems in improving the healthfulness of choices from a large set of products (as commonly encountered in a grocery store) in a realistic retail-lab setting. Findings suggest that FOP systems can help consumers accurately differentiate between objectively good, moderate, and poor nutrition products (versus control conditions) even in more complex decision environments. While evaluative formats generally outperformed reductive formats in the complex retail setting, managers should consider the distinct benefits of evaluative versus reductive FOP systems as both types of systems can be effective under different conditions.

The current research may also aid retailers' and/or manufacturers' decisions about which type of FOP system to implement. Our findings suggest that consumers with higher nutrition consciousness (NC) can use either evaluative or reductive FOP systems to accurately differentiate between good, moderate, and poor nutrition products in a choice set. However, the evaluative FOP system was or "marketing" claims), as

consumers use this

information to make

judgments and decisions about products. What factors influence these credibility beliefs and/or can enhance credibility?

Considering the prevalence of online grocery shopping services, future research should explore how FOP systems operate in a variety of simulated shopping contexts (e.g., retail lab vs eretail experiments).

Additionally, as differing FOP system types are introduced in the marketplace, quasiexperiments with scanner data would be helpful in understanding the effects on actual consumer purchase behavior and differences across more and less healthful categories.
Future research should examine other intervening variables that may mediate or moderate FOP effects such as: literacy, consumer goals (e.g., taste vs. health vs. price), and processing challenges faced by vulnerable populations. These factors may impact and potentially moderate effects of FOP systems, at 
Nutrition Facts panel. Also, shoppers can become less price sensitive and more promotion sensitive after implementation of a simplified point-of-sale nutrition scoring system. Further, some effects were moderated by category type and within-category variability in the products' nutrition scores. more beneficial than the reductive FOP system to those with lower NC. Thus, firms should consider their customers' general level of $\mathrm{NC}$ (in addition to the processing context) in order to choose the most appropriate system. least under certain conditions. The testing of more complicated serial mediation models to better understand the complexity of how FOP systems operate for various consumer segments would also be a fruitful area for future research.

Study $1 b$ extended these findings by examining FOP effects when the differences between the objective nutrition profiles were less dramatic. Here, the evaluative FOP information was less definitive due to more moderate levels of sodium and sugar (e.g., amber, rather than green or red, coding on the traffic light; less differentiation in the number of stars) and led to less discrimination between alternatives. Accordingly, the effects associated with the reductive Facts-Up-Front (FUF) icons exceeded those of the evaluative IOM stars icon in some instances. The higher levels of calories and saturated fat disclosed in the reductive formats-nutrition attributes that are very important to many consumers-probably led to somewhat stronger differentiation between healthy and unhealthy options. Relative to the other studies in Table 5, this illustrates how the specific controlled differences in objective nutrition profiles lead to some inconsistent effects across FOP label types. It also raises an important issue for food marketers and public health officials to consider regarding any evaluative disclosure: simplifying quantitative nutrient information to an interpretive ordinal (green, amber, or red) or dichotomous (does or does not qualify for a "star") level is somewhat subjective. Not all nutritionists, food companies, and public health officials will agree upon any one set of standards to be used for the criterion (i.e., cut-off) levels, so summarized evaluations will lead some consumers to arrive at different perceptions at times.

Unlike most of the experiments in Table 5, Studies 2 and 3 extended findings to a comparative context in which participants assessed multiple products at once in a simulated grocery store environment. Results reaffirmed that either reductive or evaluative FOP formats can benefit consumers' evaluations relative to the NFP alone; however, the evaluative format generally outperformed the reductive format in this more complex retail setting. Also, the effect of an evaluative FOP icon on intentions to purchase a more nutritious product was shown to be mediated by healthfulness perceptions. Adding a reductive icon to packages that already offer an evaluative icon did not have an incremental favorable effect (i.e., no interaction) on evaluations for a relatively large set of products. This suggests that greater amounts of (combined) FOP information may not offer any substantial additional benefits, and may even potentially increase consumer confusion.

\section{Implications for marketers}

The current research provides implications for CPG manufacturers and retailers that extend beyond those offered by prior research (see Table 5). Our overall pattern of results reaffirm that each type of FOP system appears to have positive features that benefit consumers. Yet, our results show the level of 
these favorable effects will still vary somewhat across contexts for each system (Andrews et al. 2011; Tellis 2017). For example, evaluative icons seem to offer somewhat greater benefits than reductive icons for more difficult product comparison tasks at the retail shelf. Here, many consumers could benefit from a summarized evaluation of the nutrient data, such as the one constructed by the IOM (even if downgrading the ratio-scaled nutrition data to ordinal/dichotomous information may be debated among food marketers and policy communities).

However, because the use of FOP labeling is voluntary, both retailers and CPG manufacturers have discretion regarding whether to use a FOP system (and if so, which specific system to use). Retailers that opt to voluntarily provide FOP nutrition information may experience more positive evaluations and higher patronage from consumers (Newman et al. 2014). Retailers may also be able to use FOP labeling in their private brand strategies as a non-price competitive advantage (Newman et al. 2014). Both CPG manufacturers and retailers, alike, should further consider how the use of FOP labeling may affect other positioning strategies (e.g., those centered on taste or price). For example, will adding a FOP icon suggesting that the product is healthy for a product promoted as tasty increase its perceived healthfulness but compromise some consumers' taste expectations (cf. Raghunathan, Naylor, and Hoyer 2006)? Firms specifically seeking to position themselves as promoting consumer health may benefit the most from use of evaluative FOP systems. Evaluative FOP icons may increase the perceived healthfulness of their offerings, relative to less healthful competitors, amidst growing consumer demand and willingness-to-pay for healthier foods (Nielsen 2015). CPG manufacturers may also seek to reformulate some of their products to qualify for certain FOP label criteria (e.g., to qualify for more Healthy Stars). However, using FOP labeling in a manner not consistent with products' objective profiles may mislead consumers, as seen previously with the dichotomous Smart Choices icon (e.g., Andrews et al. 2014). This makes the food marketer a target for negative publicity and can potentially have an unfavorable impact on firm and/or brand equity..

\section{Implications for consumer health and policy}

If increasing product evaluations and purchase intent for healthy items for a broad sector of the population is a goal from a consumer health/policy perspective, evaluative FOP formats probably offer the greatest benefit across both comparative and non-comparative tasks. Our results show across all studies that an evaluative format is strong in differentiating more and less objectively nutritious products, a factor that is critical to overall long-term consumer health. In addition, the interpretation of numerous options in a choice set offered by evaluative FOP icons at the retail shelf probably becomes even more beneficial to consumer judgments and long-term health (e.g., Federal Register 2010; Newman et al. 2014). For any evaluative icon not presenting reductive information, the specific nutrient data are always available in the NFP (assuming it is accessed).

As noted earlier, not all consumer segments are likely to evaluate nutrition information in an equivalent fashion, regardless of the format and simplicity in which the information is offered. In Studies $1 \mathrm{a}$ and $1 \mathrm{~b}$, the interaction between the FOP format condition and nutrition consciousness was superseded by the objective product level and nutrition consciousness interaction. Generally, consumers often have different goals for food choices, and they must have the interest and desire to use nutrition information when making product evaluations - even when it is presented in the most accessible and easily interpreted format. However, while there are some differences, the pattern of results across all of our studies broadly suggests that FOP information simplifies consumers' tasks and can be helpful in product evaluations. Also, as shown in Figs. 5 and 6, and consistent with prior 
nutritional labeling studies, nutrition consciousness moderates how objective disclosures are utilized in evaluations of food products (cf. Andrews et al. 2011; Keller et al. 1997).

\section{Limitations and future research}

We performed four controlled online and retail laboratory experiments. While the stimuli and FOP disclosures were realistic, and the retail environment increased external validity beyond many studies in Table 5 (e.g., Andrews et al. 2011; Kees et al. 2014), consumers at home or in actual retail stores may choose to not examine any package information in depth and, instead, focus on other promotional or contextual cues. Comparisons to in-store and other contexts would be of interest. Also, while we addressed effects for numerous dependent variables using a design in Studies $1 \mathrm{a}$ and $1 \mathrm{~b}$ that was much larger than most reported in the FOP literature (with six FOP/nutrition disclosure conditions across three objective nutrition profile levels), our results may not extend beyond the specific FOP formats, nutrition profiles, and outcomes examined. Also, the somewhat small sample size used for these large study designs may serve as a limitation for assessing complex, higher-order interaction patterns.

There are also likely to be new icons developed to differentiate products due to unregulated environments in most countries. Testing these new icons, as well as systems that further integrate reductive and evaluative components (as we attempted in Study 3), will be of interest in future research. Also, how the various FOP systems interact with explicit nutrient content and health claims, as well as other implied claims, also warrants future examination (e.g., Berry, Burton, and Howlett 2017). Consumers may not always view FOP information as believable, so examining the perceived credibility of differing FOP systems is of interest as the package environment becomes more crowded.

We also used a simple measure of nutrition consciousness drawn from the literature, but future studies may examine FOP effects related to literacy, objective nutrition knowledge, specific consumer goals, and processing challenges faced by vulnerable populations (cf. Viswanathan et al. 2009; Burton, Garretson, and Velliquette 1999). For example, many consumers have goals related to taste, and marketing managers must balance the desire for taste, health, and other food attributes. Many consumers also have an unhealthy-taste intuition (Raghunathan, Naylor, and Hoyer 2006) that may impact and potentially moderate effects of FOP labels, at least under certain conditions. Future research that addresses the many complex relationships between FOP formats, consumer goals, taste perceptions, unhealthy-taste inferences, FOP believability, and more complicated serial mediation models remain of interest. ${ }^{9}$ Levels of brand equity and prior attitudes for the actual brands used in Study 3 may also influence results and could also moderate FOP effects.

In summary, food manufacturers, public health officials, and federal agencies are keenly interested in FOP labeling effects (Andrews et al. 2014; Federal Register 2010). However, many questions regarding FOP nutrition symbols remain, and unfortunately no one study can easily address all of the opportunities and limitations mentioned here (especially in the context of between-subjects experiments designed to provide causal insights). However, we hope our findings will contribute to identifying a FOP labeling system that clearly communicates important nutrition information that aids in evaluations and decisions and improves the long-term health of consumers. 


\section{Footnotes}

1. For convenience, we offer a listing of acronyms and abbreviations used in this manuscript in Web Appendix A1.

2. To support these proposed conceptual differences in diagnosticity suggested in Figure 1, we performed an online pilot study that we present as part of our Study 1a methodology.

3. While literature often advocates use of the quantitative measure in analyses via moderated regression, in complex designs (including 6 conditions for a single factor and 18 conditions overall), this becomes untenable (e.g., the coding of a manipulated factor necessitates 5 dummy variables for a single factor and then interaction terms must be created with each of the dummy variables).

4. Conceptually, perceived healthfulness potentially mediates the interaction of the FOP and objective nutrition profile (ONP) effect on purchase intention (e.g., Burton et al. 2015). Given the $6 \times 3$ experimental design, the use of regression procedures to examine this mediation effect is untenable (Hayes 2013). But as shown in Table 2, the (1) significant interaction of the FOP and ONP for healthfulness and nutrient evaluations (the "a" path in a mediation analysis), and $(2)$ the significant positive correlations $(p<.01)$ between healthfulness and purchase intent (the " $b$ " path), suggest a significant $a * b$ path that would support moderated mediation (Hayes 2013). We explicitly test this mediation in Study 3, which uses an experimental design more amenable to testing moderated mediation using regression.

5. Unlike the objective nutrition profile, the FOP*NC interaction reaches a .05 level of significance for only one nutrient. This pattern suggests that effects of NC across FOP information (which is designed to simplify nutrition information) are more similar than the moderating effect of NC for the objective profile information disclosed in the NFP.

6. While the moderating role of FOP did not reach a level of significance for the overall product healthfulness, there was a significant difference (all $p<.05$ ) between the objective profiles for the NFP only control, the FUF, the green FUF, and the traffic light (Fs range from 3.32 [for the FOP control] to 4.75 [all green FUF]). Contrasts showed that the Good profile exceeded the Poor objective profile. The full nutrition control and the IOM stars did not reach significance.

7. Given these findings, we also performed a simple mediation test for the evaluative icon (Hayes 2013). Results of this test indicated that the indirect effect for stars icon $\rightarrow$ healthfulness $\rightarrow$ purchase intentions was significant (IE $=.33, \mathrm{Cl}[.09, .75])$, and that the positive direct effect of the stars icon on intentions to purchase the focal healthful product also remains significant $(p<.03)$ with the mediator included in the model (i.e., partial mediation).

8. We also had participants choose the one most preferred item from the set of nine packages on the retail shelf (i.e., "Which one granola bar would you be most likely to purchase?"). A nutritious Good product was chosen more often when the stars and FUF (44\%) or stars alone (40\%) were available on the packages, relative to the no icon control (17\%; all $z=2.15$ and 1.86, respectively; all $p<.05)$. There was no significant difference between these two choice percentages ( $44 \%$ vs. $40 \% ; p>.70$ ), again suggesting that providing the more quantitative FUF icon together with the evaluative icon offers no incremental benefit. Inclusion of the FUF icon, alone, appeared to slightly increase selection of the objectively more nutritious product (33\%) when compared to the no icon control, but it did not reach significance $(z=1.32, p=.09)$.

9. Based on reviewers' suggestions, we conducted an initial exploratory study addressing the role of explicit goals in a 2 (goal: taste vs. health) $\times 2$ (FOP format: reductive FUF icon vs. evaluative stars icon) $\times 3$ (objective nutrition level: poor, moderate, good) mixed design for a frozen food 
product. As expected, while the "good" objective level decreased taste perceptions, and the goal and taste perceptions affected purchase intention, the specific FOP format did not interact with the goal. Further, for purchase intentions, the unhealthy-tasty intuition (Raghunathan et al. 2006), did not interact with the FOP format or objective nutrition level, and perceived credibility of the FOP format did not affect intent.

\section{References}

1. Alba, J., Hutchinson, J. W., \& Lynch, J. (1991). Memory and decision making. In T. Robertson \& H. Kassarjian (Eds.), Handbook of Consumer Behavior (pp. 1-49). Englewood Cliffs: PrenticeHall.Google Scholar

2. Andrews, J. C., Netemeyer, R. G., \& Burton, S. (2009). The nutrition elite: Do only the highest levels of caloric knowledge, obesity knowledge, and motivation matter in processing nutrition ad claims and disclosures? Journal of Public Policy \& Marketing, 28(1), 41-55.CrossRefGoogle Scholar

3. Andrews, J. C., Burton, S., \& Kees, J. (2011). Is simpler always better? Consumer evaluations of front-of-package nutrition symbols. Journal of Public Policy \& Marketing, 30, 175190.CrossRefGoogle Scholar

4. Andrews, J. C., Lin, C. J., Levy, A. S., \& Lo, S. (2014). Consumer research needs from the food and drug administration on front-of-package nutritional labeling. Journal of Public Policy \& Marketing, 33(1), 10-16.CrossRefGoogle Scholar

5. Berry, C., Burton, S., \& Howlett, E. (2017). It's only natural: the mediating impact of consumers' inferential beliefs on the relationships between product claims, perceived product healthfulness, and purchase intentions. Journal of the Academy of Marketing Science, 45(5), 698-719.CrossRefGoogle Scholar

6. Bialkova, S., Grunert, K. G., Juhl, H. J., Wasowicz-Kirylo, G., Stysko-Kunkowska, M., \& van Trijp, H. C. M. (2014). Attention mediates the effect of nutrition label information on consumers' choice. Evidence from a choice experiment involving eye-tracking. Appetite, 76(1), 6675.CrossRefGoogle Scholar

7. Bittman, M. (2014). Parasites, killing their host: the food industry's solution to obesity. New York Times, available at https://www.nytimes.com/2014/06/18/opinion/mark-bittmanthefood-industrys-solution-to-obesity.html

8. Burton, S., Garretson, J. A., \& Velliquette, A. M. (1999). Implications of accurate usage of nutrition facts panel information for food product evaluations and purchase intentions. Journal of the Academy of Marketing Science, 27(4), 470-480.CrossRefGoogle Scholar

9. Burton, S., Creyer, E. H., Kees, J., \& Huggins, K. (2006). Attacking the obesity epidemic: the potential health benefits of providing nutrition information in restaurants. American Journal of Public Health, 96(9), 1669-1675.CrossRefGoogle Scholar

10. Burton, S., Cook, L. A., Howlett, E., \& Newman, C. L. (2015). Broken halos and shattered horns: overcoming the biasing effects of prior expectations through objective information disclosure. Journal of the Academy of Marketing Science, 43(2), 240-256.CrossRefGoogle Scholar

11. CDC (2017). Overweight and Obesity. U.S. Department of Health and Human Services, September [http://www.cdc.gov/nccdphp/dnpa/obesity/index.htm].

12. Chandon, P., \& Wansink, B. (2007). Is obesity caused by calorie underestimation? a psychophysical model of meal size estimation. Journal of Marketing Research, 44(1), 8499.CrossRefGoogle Scholar 
13. Ducrot, P., Julia, C., Méjean, C., Kesse-Guyot, E., Touvier, M., Fezeu, L. K., \& Péneau, S. (2016). Impact of different front-of-pack nutrition labels on consumer purchasing intentions: a randomized controlled trial. American Journal of Preventive Medicine, 50(5), 627636.CrossRefGoogle Scholar

14. Dzhogleva, H., \& Inman, J. J. (2015). Healthy choice: the effect of simplified pos nutritional information on consumer choice behavior. Journal of Marketing Research, 52, 817835.CrossRefGoogle Scholar

15. Eagly, A. H., \& Chaiken, S. (1993). The psychology of attitudes. Orlando: Harcourt Brace Jovanovich College Publishers.Google Scholar

16. European Union Food Information Council (2015) "Global update on nutrition labelling. [available at: http://www.eufic.org/upl/1/default/doc/GlobalUpdateExecSumJan2015.pdf].

17. Facts-Up-Front (2014). What is facts up front?" (accessed December 15, 2016), [available at http://www.factsupfront.org/].

18. FDA (2011). Letter of enforcement discretion to gma/fmi re 'facts up front,'” Taylor, M. R. (Deputy Commissioner for Foods), U.S. Food and Drug Administration, (December 13), (accessed December 30, 2016), [available at http://www.fda.gov/Food/IngredientsPackagingLabeling/LabelingNutrition/ucm302720.htm].

19. Federal Register (2010). Front-of-pack and shelf tag nutrition symbols; establishment of docket: request for comments and information. 75 (82) (April 29), U.S. Department of Health \& Human Services, U.S. Food \& Drug Administration, 22602-22606.Google Scholar

20. Feunekes, G. I. J., Gortemaker, I. A., Willems, A. A., Lion, R., \& Kommer, M. (2008). Front-ofpack nutrition labelling: testing effectiveness of different nutrition labelling formats front-ofpack in four european countries. Appetite, 50(1), 57-70.CrossRefGoogle Scholar

21. Finkelstein, E. A., Khavjou, O. A., Thompson, H., Trogdon, J. G., Pan, L., Sherry, B., \& Dietz, W. (2012). Obesity and severe obesity forecasts through 2030. American Journal of Preventive Medicine, 42(6), 563-570.CrossRefGoogle Scholar

22. Goodman, J. K., \& Paolacci, G. (2017). Crowdsourcing consumer research. Journal of Consumer Research, 44(1), 196-210.CrossRefGoogle Scholar

23. Graham, D., Heidrick, C., \& Hodgin, K. (2015). Nutrition label viewing during a food-selection task: front-of-package labels vs nutrition facts labels. Journal of the Academy of Nutrition and Dietetics, 115(10), 1636-1646.CrossRefGoogle Scholar

24. Grocery Manufacturers of America (GMA) (2011). Food and beverage industry launches nutrition keys front-of-pack nutrition labeling initiative to inform consumers and combat obesity. Press Release. http://www.gmaonline.org/news-events/newsroom/food-andbeverage-industry-launches-nutrition-keys-front-of-pack-nutrition- (accessed November 17, 2016).

25. Hayes, A. F. (2013). Introduction to Mediation, Moderation, and Conditional Process Analysis, New York. New York: Guilford.Google Scholar

26. lacobucci, D., Posavac, S. S., Kardes, F. R., Schneider, M. J., \& Popovich, D. L. (2015). Toward a more nuanced understanding of the statistical properties of a median split. Journal of Consumer Psychology, 652-665.Google Scholar

27. Institute of Medicine (IOM) (2011). Examination of front-of-package nutrition rating systems and symbols. (October 18), (accessed March 11, 2014), [available at http://www.iom.edu/Activities/Nutrition/NutritionSymbols.aspx]. 
28. Kees, J., Royne, M. B., \& Cho, Y. (2014). Regulating front-of-package nutrition information disclosures: a test of industry self-regulation vs. other popular options. Journal of Consumer Affairs, 48(Spring), 147-174.CrossRefGoogle Scholar

29. Kees, J., Burton, S., \& Andrews, J. C. (2015). Government efforts to aid consumers' well-being: understanding federal health warnings and disclosures. in the Cambridge Handbook of Consumer Psychology (Eds.), Michael Norton, Derek Rucker, and Cait Lamberton, 530562.Google Scholar

30. Kees, J., Berry, C., Burton, S., \& Sheehan, K. (2017a). An analysis of data quality: Professional panels, student subject pools, and Amazon's Mechanical Turk. Journal of Advertising, 46(1), 141-155.CrossRefGoogle Scholar

31. Kees, J., Berry, C., Burton, S., \& Sheehan, K. (2017b). Reply to Amazon's Mechanical Turk: a comment. Journal of Advertising, 46(1), 159-162.CrossRefGoogle Scholar

32. Keller, S. B., Landry, M., Olson, J., Velliquette, A. M., Burton, S., \& Andrews, J. C. (1997). The effects of nutrition package claims, nutrition facts panels, and motivation to process nutrition information on consumer product evaluations. Journal of Public Policy \& Marketing, 16(Fall), 256-269.Google Scholar

33. Kozup, J., Creyer, E. H., \& Burton, S. (2003). Making healthful food choices: the influence of health claims and nutrition information on consumer's evaluations of packaged food products and restaurant menu items. Journal of Marketing, 67, 19-34.CrossRefGoogle Scholar

34. Mitra, A., Hastak, M., Ford, G. T., \& Ringold, D. J. (1999). Can the educationally disadvantaged interpret the FDA-mandated nutrition facts panel in the presence of an implied health claim? Journal of Public Policy \& Marketing, 18(Spring), 106-117.Google Scholar

35. Nielsen (2015), "We Are What We Eat: Healthy Eating Trends Around the World," (accessed July 7, 2017), [available at www.nielsen.com/content/dam/nielsenglobal/eu/nielseninsights/pdfs/Nielsen\%20Global\%2OH ealth\%20and\%20Wellness\%20Report\%20\%20January\%202015.pdf].

36. Newman, M. A. (2000). Health as Expanding Consciousness. Sudbury: Jones and Bartlett.Google Scholar

37. Newman, C. L., Howlett, E., \& Burton, S. (2014). Shopper response to front-of-package nutrition labeling programs: potential consumer and retail store benefits. Journal of Retailing, 90(1), 1326.CrossRefGoogle Scholar

38. Newman, C. L., Howlett, E., \& Burton, S. (2016). The effects of objective and evaluative front-ofpackage cues on food evaluation and choice: the moderating influence of comparative and noncomparative processing contexts. Journal of Consumer Research, 42, 749-766.CrossRefGoogle Scholar

39. Nutrition Labeling and Education Act (NLEA) (1990), Public Law No. 101-535, 104 Stat. 2353 (codified in part at 21 U.S.C. 343).Google Scholar

40. NuVal (2014). ONQI: The science behind the scores. (accessed June 11, 2016), [available at http://www.nuval.com/science].

41. Ogden, C. L., Carroll, M. D., Kit, B. K., \& Flegal, K. M. (2014). Prevalence of childhood and adult obesity in the united States, 2011-2012. Journal of the American Medical Association, 311(8), 806-814.CrossRefGoogle Scholar

42. Pettigrew, S., Talati, Z., Miller, C., Dixon, H., Kelly, B., \& Ball, K. (2017). The types and aspects of front-of-pack food labelling schemes preferred by adults and children. Appetite, 109(February), 115-123.CrossRefGoogle Scholar 
43. Petty, R. E., \& Cacioppo, J. T. (1986). The elaboration likelihood model of persuasion. Communication and Persuasion (pp. 1-24). New York: Springer.Google Scholar

44. Raghunathan, R., Naylor, R. W., \& Hoyer, W. D. (2006). The unhealthy = tasty intuition and its effects on taste inferences, enjoyment, and choice of food products. Journal of Marketing, 70(4), 170-184.CrossRefGoogle Scholar

45. Scammon, D. (1977). Information load and consumers. Journal of Consumer Research, 4(3), 148-155.CrossRefGoogle Scholar

46. Sebolt, A. (2008). Standardized nutrition: food business groups seek uniform symbols on packaging. Food Business News, June 10. [Available at http://www.foodbusinessnews.net/ feature_stories_print.asp?ArticlelD=94121].

47. Stanish, J.R. (2010). The obesity epidemic in America and the responsibility of big food manufacturers. Inquiries Journal, 2 (11). (Available at www.inquiriesjournal.com/articles/320/ the-obesity-epidemic-in-america-and-the-responsibility-of-big-food-manufacturers.

48. Tellis, G. J. (2017). Interesting and impactful research: on phenomena, theory, and writing. Journal of the Academy of Marketing Science, 45(1), 1-6.CrossRefGoogle Scholar

49. van Horen, F., \& Pieters, R. (2012). When high-similarity copycats lose and moderate-similarity copycats gain: the impact of comparative evaluation. Journal of Marketing Research, 49(1), 8391.CrossRefGoogle Scholar

50. Viswanathan, M., Hastak, M., \& Gau, R. (2009). Understanding and facilitating the usage of nutritional labels by low-literate consumers. Journal of Public Policy and Marketing, 28(2), 135145.CrossRefGoogle Scholar

51. Wilkie, W. L., \& Moore, E. S. (2012). Expanding our understanding of marketing in society. Journal of the Academy of Marketing Science, 40(1), 53-73. 